\title{
Prediction of Holdup and Drop Size Distribution in a Disc-Doughnut Pulsed Column with Tenova Kinetics Internals for the Water-Alamine
}

\author{
336 System
}

\author{
Wen $\mathrm{Li}^{1}$, Yong Wang ${ }^{1}$, Kathryn A. Mumford ${ }^{1}$, Kathryn H. Smith ${ }^{1}$, Geoffrey W. Stevens ${ }^{1, *}$ \\ ${ }^{1}$ Department of Chemical and Biomolecular Engineering, The University of Melbourne, Parkville, VIC 3010, \\ Australia \\ *Corresponding author. E-mail address: gstevens@unimelb.edu.au
}

\begin{abstract}
:
Tenova Pulsed Column Kinetics Internals (TPC-KIs) are a newly designed type of pulsed column internals with a novel structure that is expected to achieve less back-mixing, higher holdup and improved mass transfer. This study compared the hydrodynamic performance of TPC-KIs with standard disc and doughnut internals in a $2 \mathrm{~m}$ high $76 \mathrm{~mm}$ diameter pulsed solvent extraction column with the water-Alamine 336-Shellsol 2046 system. The effects of the wettability of column internals have also been considered. Dispersed phase holdup and Sauter mean droplet diameter were measured under various pulsation intensity and velocities of both phases, and empirical correlations for holdup and drop size have been refitted within absolute average relative errors within $15 \%$. Tenova kinetics internals has lower holdup and larger Sauter-mean drop size compared to standard disc and doughnut internals, and these hydrodynamic parameters are predictable using the developed correlation in this study.
\end{abstract}

\section{Key words:}

Solvent extraction, pulsed column, TPC-KIs, Dispersed phase holdup, Sauter mean diameter, wettability, correlation 


\section{Introduction}

Pulsed solvent extraction columns are an efficient liquid-liquid contactor design and have been studied with various types of column internals, such as Kühni column, pulsed packed column, pulsed perforated column and pulsed disc and doughnut column. As fixed components inside the pulsed column, the column internals can be produced at a low cost and operated with minimal ongoing maintenance. However, the design of these internals can significantly impact column performance and hence optimising their design is important. Additionally, when compared to other liquid-liquid separation apparatus such as mixer-settlers, pulsed columns can reduce evaporation loss, entrainment and solvent inventory to a large extent.

This study aims to compare the hydrodynamic performance of pulsed columns with Tenova Pulsed Column Kinetics Internals (TPC-KIs) and standard disc and doughnut internals using water - Alamine 336 in Shellsol 2046 liquid-liquid system (either with aqueous continuous or organic continuous operation). Wang et al. ${ }^{[2]}$ has recently reported the hydrodynamic performance of a $1 \mathrm{~m}$ high $72.5 \mathrm{~mm}$ diameter pulsed solvent extraction column with Teflon standard disc and doughnut internals using tap water - Alamine 336 in Shellsol 2046. The study found the increase in dispersed phase holdup with dispersed phase flowrate and high pulsation intensity. However, there is very limited study on the performance of pulsed columns with TPC-KIs internals. As novel column internals with improved structure, TPC-KIs are expected to improve overall mass transfer performance by producing a larger dispersed phase holdup and less axial dispersion under comparable operating conditions ${ }^{[1]}$. Due to the presence of a sawtooth edging of Tenova kinetics internals, its flood point is expected to be higher than for standard disc and doughnut internals, thus a much higher throughput can be achieved.

In the present study, polyvinylidene fluoride (PVDF) was used for both standard disc and doughnut internals and the TPC-KIs, but the surface roughness of the PVDF sheets was different for the two types of internals resulting in variation in surface wettability ${ }^{[3]}$. The wettability of these internals indicates that liquid-liquid systems can be efficiently operated under both organic continuous and aqueous continuous. The present study investigates both the influence of which phase is continuous and the internal structures on the hydrodynamic performance of a pulsed solvent extraction column.

\section{Background}

Hydrodynamics is crucial for the assessment of solvent extraction column performance as it directly influences the interfacial area available for mass transfer. A larger liquid-liquid interfacial area results in higher mass transfer 
fluxes according to the two-film theory ${ }^{[4]}$. In the present study, two significant hydrodynamics parameters, dispersed phase holdup and Sauter mean diameter are investigated. The dispersed phase holdup can be easily calculated as the ratio of the dispersed phase volume in the active section of column to the total column volume. The Sauter mean diameter indicates the average dimension of the dispersed phase droplets. This is a dynamic parameter and changes with operating conditions and column geometry. The dispersed phase enters the column and forms droplets as it passes through the column internals until an equilibrium spread of droplet sizes is reached. Additionally the droplet size and shape can be influenced by the wettability and contact of the dispersed phase with the column internals ${ }^{[5]}$.

A number of researchers have reported studies on pulsed solvent extraction columns and proposed empirical correlations for predicting the hydrodynamic performance of pulsed solvent extraction columns with different types of column internals and liquid - liquid systems (see Table 1 and Table 2). However, there is limited study using the Tenova pulsed column - kinetics internals (TPC-KIs). 
$\underline{\text { Table } 1}$ Correlations from literature for the prediction of dispersed phase holdup in pulsed Solvent extraction columns

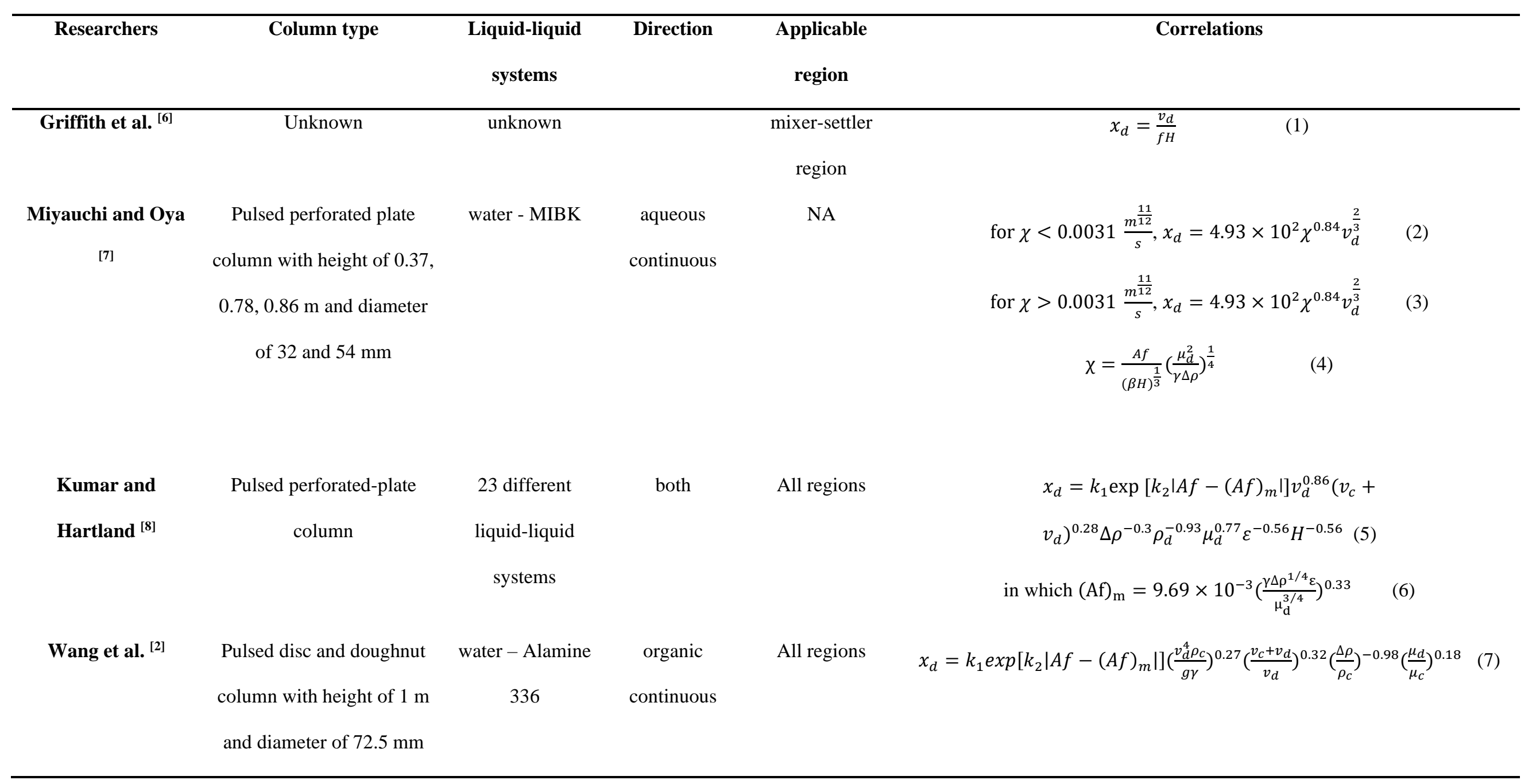


$\underline{\text { Table } 2}$ Correlations from literature for the prediction of dispersed phase drop size in pulsed solvent extraction columns

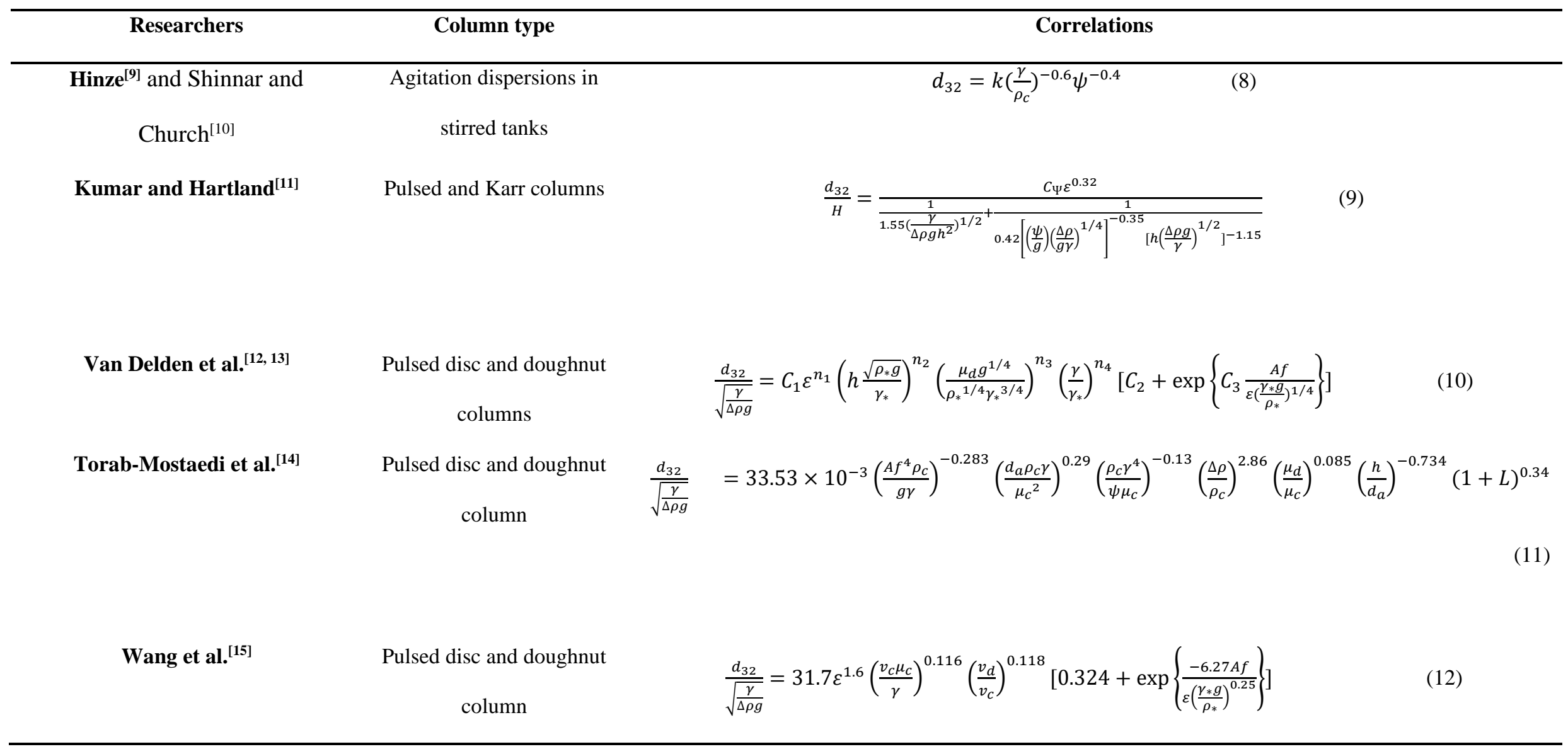




\section{Experimental}

\subsection{Liquid-liquid system}

The liquid-liquid system used in this study was tap water as the aqueous phase and 3 v/v \% Alamine® 336 (trioctyl/decyl amine, BASF), and 1 v/v \% Isodecanol (ExxonMobil), diluted with Shellsol® 2046 (Shell) as the organic phase. No mass transfer of the solute occurred in this hydrodynamic study. The physical properties of each phase including density, $\rho$, viscosity, $\mu$, and interfacial tensions $\gamma_{\mathrm{q}-\text { org }}$ were measured and results are shown

in Table 3. Densities of aqueous and organic phases were measured three times to obtain average values using 25 $\mathrm{mL}$ density bottles. A Cannon portable viscometer was used to measure the viscosity of each phase. Interfacial tension was measured with a Theta Attension Tensiometer.

Table 3 Physical properties of liquid-liquid system

\begin{tabular}{|c|c|c|c|c|c|c|}
\hline $\begin{array}{c}\text { Aqueous } \\
\text { Phase }\end{array}$ & $\begin{array}{l}\text { Organic } \\
\text { Phase }\end{array}$ & $\begin{array}{c}\rho \mathrm{aq} \\
\left(\mathrm{kg} / \mathrm{m}^{3}\right)\end{array}$ & 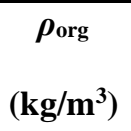 & $\mu_{\mathrm{aq}}(\mathbf{P a} \cdot \mathbf{s})$ & $\mu_{\text {org }}(\mathbf{P a} \cdot \mathbf{s})$ & $\begin{array}{l}\gamma_{\text {aq-org }} \\
(\mathrm{N} / \mathrm{m})\end{array}$ \\
\hline Tap water & $\begin{array}{c}3 \text { v/v \% Alamine } 336 \& 1 \text { v/v \% } \\
\text { isodecanol in Shellsol } 2046\end{array}$ & 998 & 801.2 & $1.02 \times 10^{-3}$ & $2.30 \times 10^{-3}$ & 0.011 \\
\hline Tap water & 8 v/v \% Lix 84 in Shellsol 2046 & 998 & 810.3 & $1.02 \times 10^{-3}$ & $2.08 \times 10^{-3}$ & 0.022 \\
\hline
\end{tabular}

\subsection{Equipment}

A $2 \mathrm{~m}$ high $76 \mathrm{~mm}$ diameter pulsed solvent extraction pilot-scale column was used to collect experimental data. The column set-up has been reported in previous study ${ }^{[3]}$. The main column consists of a concentric reducer, two $1 \mathrm{~m}$ long cylinder components and a tee piece, which was connected to the inlet from aqueous feed solution tank and the outlet of the loaded organic tank. All four column parts were made of QVF precision borosilicate glassware and connected with relevant couplings and seals. Pulsing was powered with a three-phase induction motor and connected to a zero-max gearbox from Naismith with a piston unit linked to the bottom distributor of the organic phase $^{[3]}$.

The standard disc and doughnut internals and Tenova pulsed column - kinetics internals (TPC-KIs) (see Figure 1) were placed inside the pulsed column separately in order to assess their enhancement in the breakage of dispersed phase droplets and improve the interfacial area between the two immiscible phases to enable better mass transfer performance. Seventy seven disc and seventy six doughnut plates, which were made of PVDF 
(polyvinylidene fluoride), were alternatively connected by three $10 \mathrm{~mm}$ diameter SS rods with $9.8 \mathrm{~mm}$ spacing apart. The open free area for both internals is $22.4 \%$. Pilot scale experiments were conducted at room temperature.

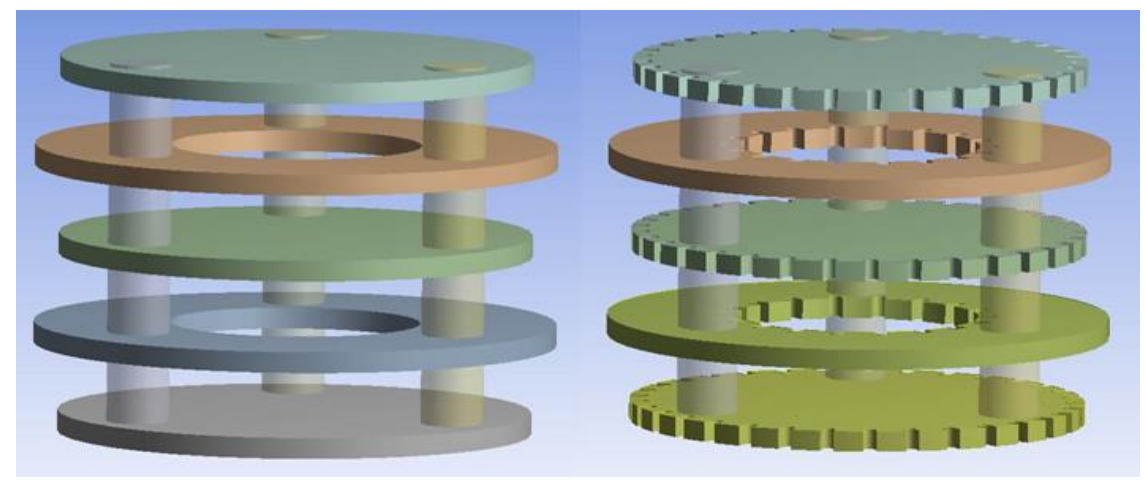

Figure 1. Schematic drawings for standard disc and doughnut internals (left) and Tenova kinetics internals (right)

\subsection{Column Operation}

The dispersed phase holdup under a wide range of operating conditions was measured using the drainage technique, which was detailed by Torab-Mostaedi (2011) ${ }^{[14]}$. At a defined pulsing amplitude and frequency and stable phase flowrates, column operation under steady state conditions was stopped by simultaneously closing the inlets and outlets for both aqueous and organic phase and turning the pulsing unit's power off. After labelling the interface level, the dispersed phase droplets remaining inside the main section of pulsed column were allowed to settle/rise to the interface level. The volume of the dispersed phase droplets present under steady state conditions were then measured with a volumetric flask via the difference between the two interface levels. The dispersed phase holdup, which is defined as the ratio of the volume of dispersed phase droplets at steady state over the total volume of the column main section, could then be calculated.

Photographs of the dispersed phase droplets were also taken at equilibrium using a Canon G16 camera with fixed focus and external speedlite at the middle of the column using a Perspex cubical viewing box. Dozens of digital photographs at each defined operating condition were taken and drop size analysed using Nano Measurer 1.2 software for a minimum 150 droplets diameter data.

The pulsation intensity was varied from $0 \mathrm{~m} / \mathrm{s}$ to $0.03 \mathrm{~m} / \mathrm{s}$, and the dispersed phase and continuous phase velocities were changed between $3.68 \times 10^{-4}$ to $1.84 \times 10^{-3} \mathrm{~m} / \mathrm{s}$ and $2.39 \times 10^{-4}$ to $1.84 \times 10^{-3} \mathrm{~m} / \mathrm{s}$, respectively. 


\section{Results and discussion}

\subsection{Dispersed phase holdup}

For the newly designed TPC-KIs, the effect of pulsation intensity on the dispersed phase holdup was studied and the results are plotted on Figure 3 for both aqueous continuous and organic continuous operation. To enable comparison between the standard disc and doughnut internals and TPC-KIs, the effect of pulsation intensity on the dispersed phase holdup with organic continuous for both internals is shown in Figure 4. The aqueous phase flow rates were varied from $7.35 \times 10^{-4}$ to $1.47 \times 10^{-3} \mathrm{~m} / \mathrm{s}$ and $6.62 \times 10^{-4}$ to $1.43 \times 10^{-3} \mathrm{~m} / \mathrm{s}$ for the continuous phase flow rates.

Figure 3 shows that the dispersed phase holdup, under all five A/O ratios, always decreases with increasing pulsation intensity to a minimum value $\left((\mathrm{Af})_{\min }=0.01 \pm 0.002 \mathrm{~m} / \mathrm{s}\right.$ for aqueous continuous series and $(\mathrm{Af})_{\min }=$ $0.02 \pm 0.002 \mathrm{~m} / \mathrm{s}$ for organic continuous series, respectively). Following this, the volume of dispersed phase droplets generally increases with pulsation intensity. At the pulsation intensity of (Af) $)_{\min }$, the lowest volume of dispersed phase is kept inside the column and therefore may limit the mass transfer rate. For the same values of dispersed phase velocity for both aqueous continuous $\left(\mathrm{v}_{\mathrm{d}}=7.35 \times 10^{-4} \mathrm{~m} / \mathrm{s}\right)$ and organic continuous $\left(\mathrm{v}_{\mathrm{d}}=6.62 \mathrm{x}\right.$ $10^{-4} \mathrm{~m} / \mathrm{s}$ ), the data series are in good agreement with each other ${ }^{[3]}$. Holdup results at $\mathrm{v}_{\mathrm{d}}=7.35 \times 10^{-4} \mathrm{~m} / \mathrm{s}$ for the organic continuous system were higher than that at $\mathrm{v}_{\mathrm{d}}=6.62 \times 10^{-4} \mathrm{~m} / \mathrm{s}$ for aqueous continuous system. Similarly, holdup data at $\mathrm{v}_{\mathrm{d}}=1.43 \times 10^{-3} \mathrm{~m} / \mathrm{s}$ for the aqueous continuous system was lower than the holdup at $\mathrm{v}_{\mathrm{d}}=1.47 \mathrm{x}$ $10^{-3} \mathrm{~m} / \mathrm{s}$ for the organic continuous system. To have improved overall mass transfer performance, it is beneficial to maintain a higher dispersed phase holdup in the working section of the column as it results in a larger interfacial area between the two immiscible phases. Hence, choosing the organic continuous system would be a wise option for PVDF Tenova Pulsed Column - Kinetics Internals. 


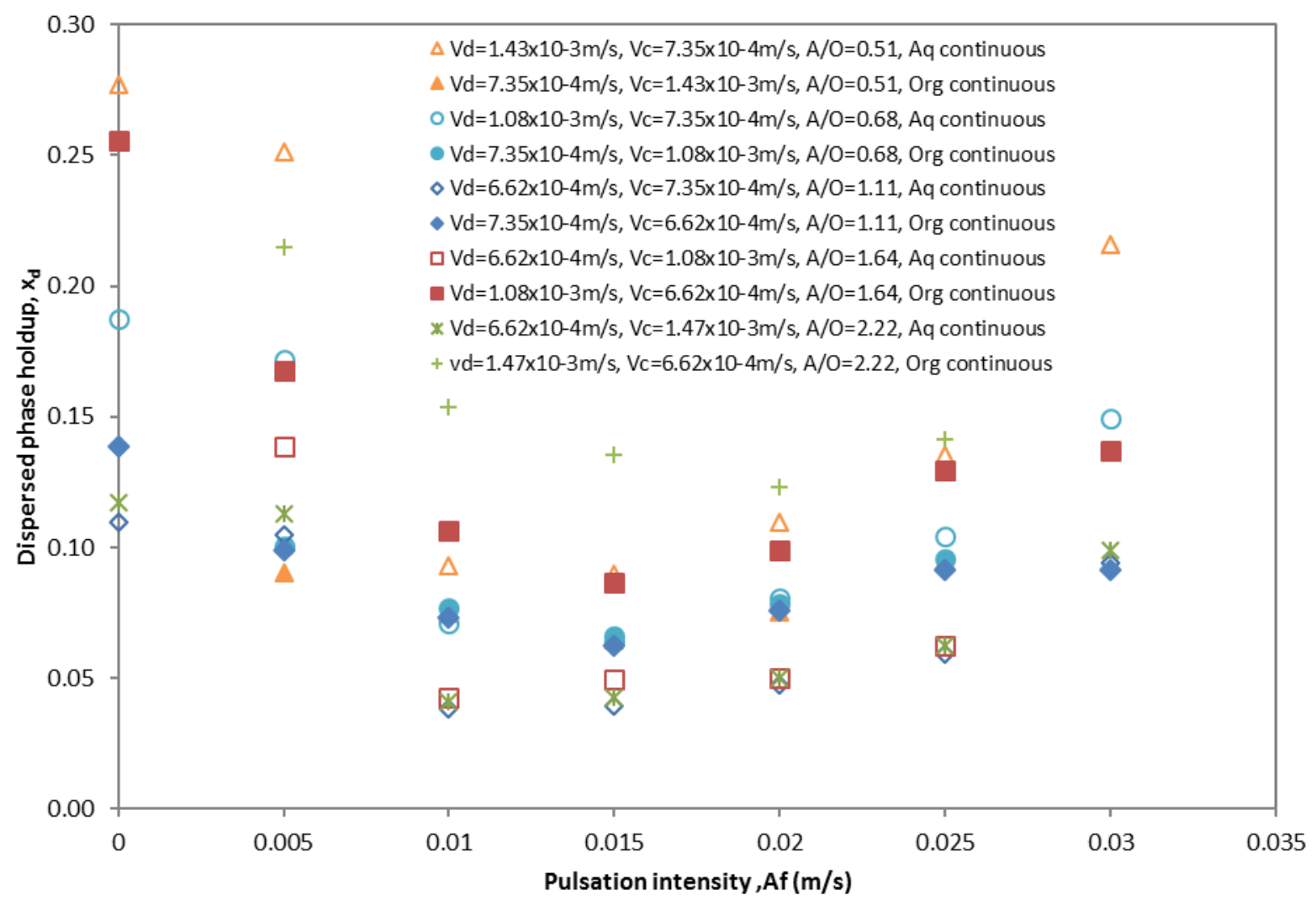

Figure 3. Effect of pulsation intensity and dispersed phase velocity on the dispersed phase holdup $\mathrm{x}_{\mathrm{d}}$ for Tenova pulsed column kinetics internals

Figure 4 presents dispersed phase holdup as a function of pulsation intensity for the different internals at the same operating conditions. A slightly lower dispersed phase holdup was measured with TPC-KIs at low pulsation intensity ( Af $\leqslant 0.015 \mathrm{~m} / \mathrm{s}$ ) compared to the standard disc and doughnut internals, but higher holdup was measured when the pulsation intensity was increased above $0.015 \mathrm{~m} / \mathrm{s}$. For both sets of internals, the dispersed phase holdup dropped to a minimum value at a constant pulsation intensity (for standard disc and doughnut internals, $(\mathrm{Af})_{\min }=$ $0.02 \pm 0.002 \mathrm{~m} / \mathrm{s}$; for TPC-KIs, (Af $)_{\min }=0.015 \pm 0.002 \mathrm{~m} / \mathrm{s}$ ). It was also found that there was little effect of the continuous phase velocity on the dispersed phase holdup but an obvious effect of the dispersed phase velocity. 


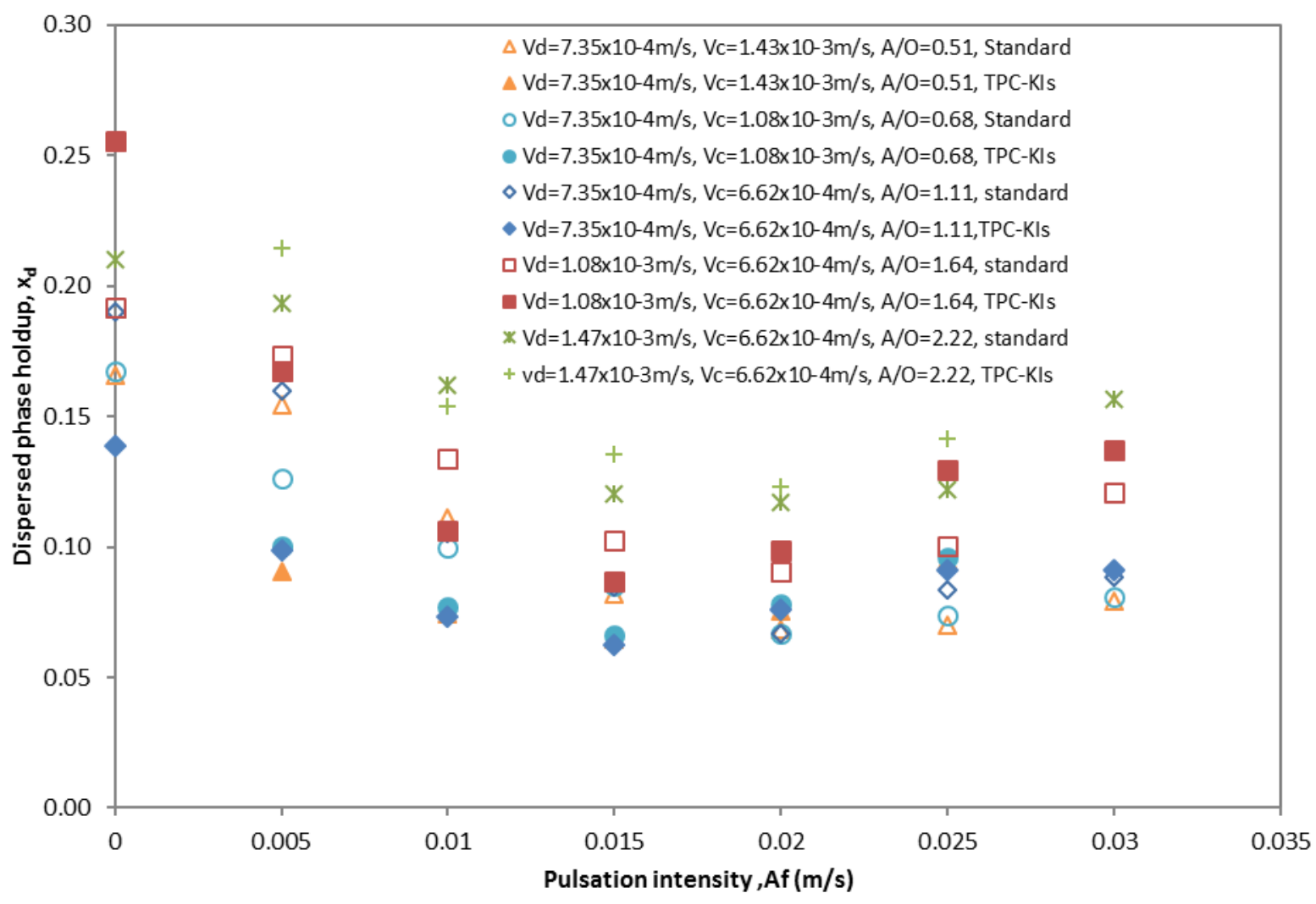

Figure 4. Effect of pulsation intensity and continuous phase velocity on the dispersed phase holdup $\mathrm{x}_{\mathrm{d}}$ for different column internals

Figure 5 and 6 shows how the dispersed phase velocity and continuous phase velocity influenced the dispersed phase holdup for the different internals at a constant pulsation intensity of $0.01 \mathrm{~m} / \mathrm{s}$. For the same continuous phase velocity of $6.62 \times 10^{-4} \mathrm{~m} / \mathrm{s}$, the holdup for both standard disc and doughnut internals and Tenova kinetics internals keeps linearly with dispersed phase velocity. The dispersed phase holdup for both sets of internals also increases at a similar rate, although the standard disc and doughnut generally provided slightly higher holdup at these operating conditions (which is at a relatively low pulsation rate of $0.01 \mathrm{~m} / \mathrm{s}$ ).

The effect of continuous phase velocity on dispersed phase holdup with a dispersed phase velocity of $7.35 \times 10^{-4}$ $\mathrm{m} / \mathrm{s}$ is presented in Figure 6, and it can be concluded that varying the continuous phase velocity did not show an observable effect on holdup with either set of internals. 


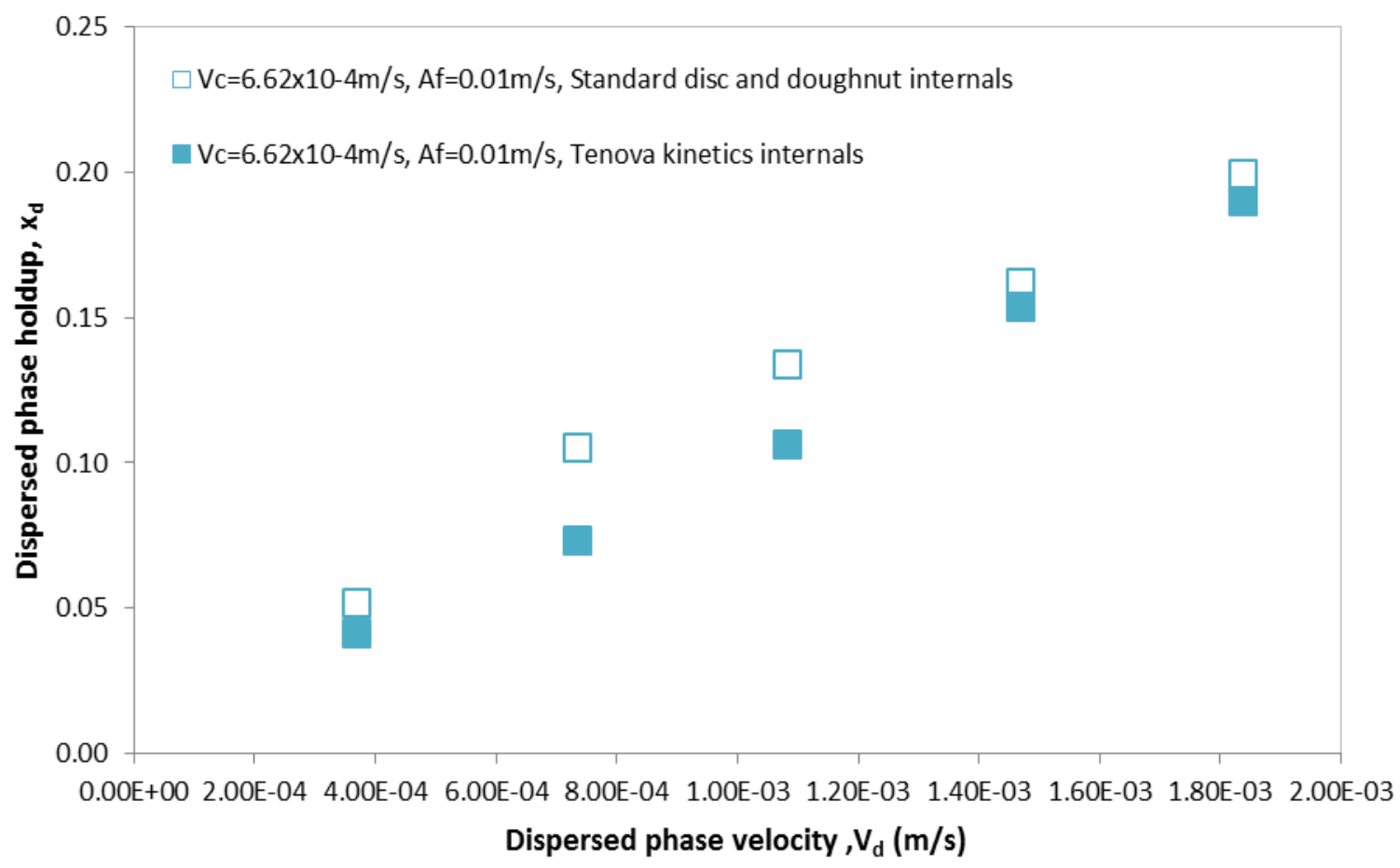

Figure 5. Effect of dispersed phase velocity on dispersed phase holdup at constant continuous phase velocity $\left(\mathrm{v}_{\mathrm{c}}=6.62 \times 10^{-}\right.$ $\left.{ }^{4} \mathrm{~m} / \mathrm{s}\right)$ and pulsation intensity $(\mathrm{Af}=0.01 \mathrm{~m} / \mathrm{s})$

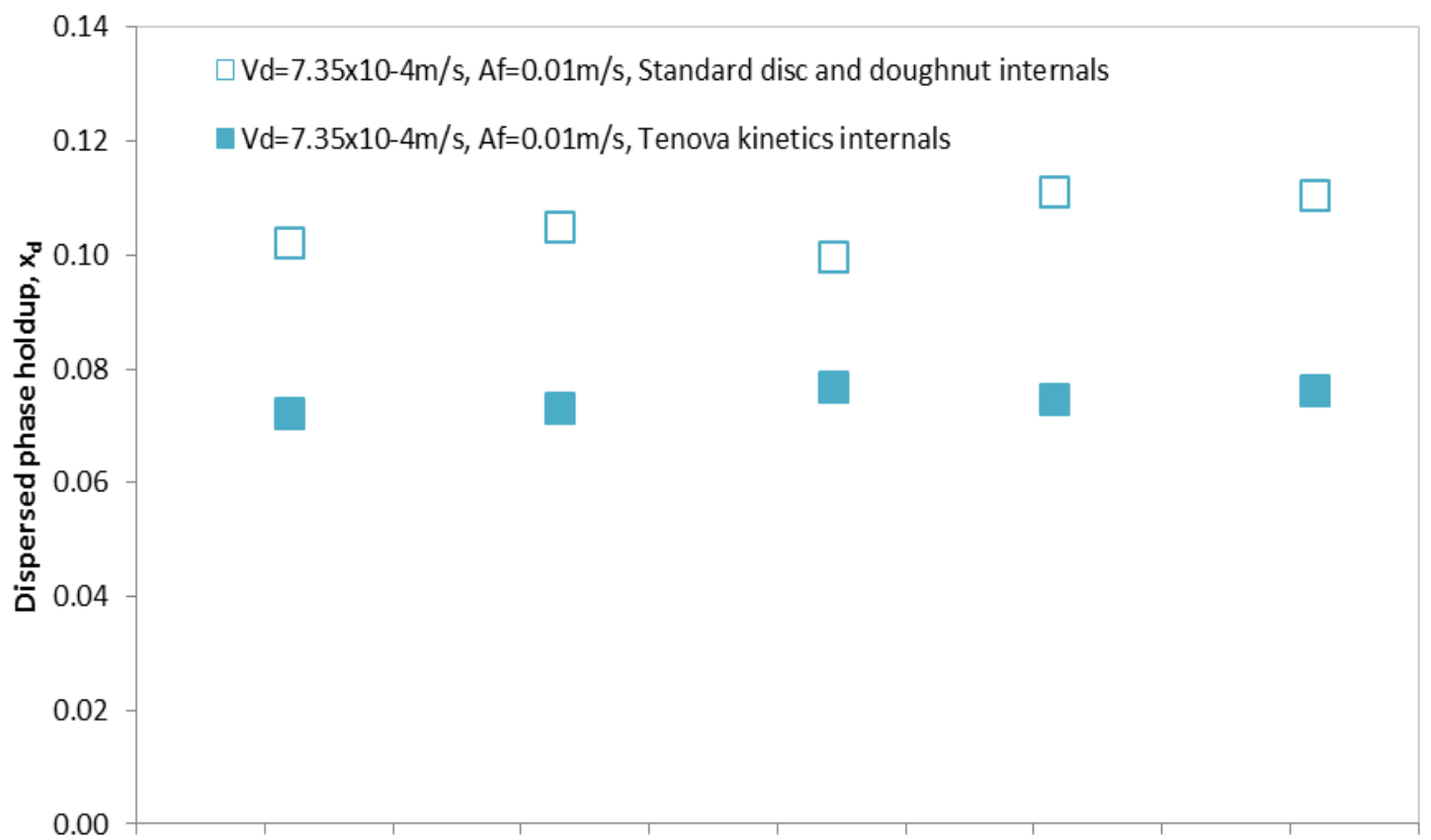

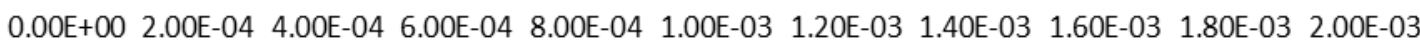
Continuous phase velocity, $\mathrm{V}_{\mathrm{c}}(\mathrm{m} / \mathrm{s})$

Figure 6. Effect of continuous phase velocity on dispersed phase holdup under same dispersed phase velocity $\left(\mathrm{v}_{\mathrm{d}}=7.35 \times 10^{-}\right.$ $\left.{ }^{4} \mathrm{~m} / \mathrm{s}\right)$ and pulsation intensity $(\mathrm{Af}=0.01 \mathrm{~m} / \mathrm{s})$ 


\subsection{Correlation for dispersed phase holdup}

An empirical correlation for prediction of the dispersed phase holdup with standard disc and doughnut internals and Tenova Pulsed Column - Kinetics Internals was reported using a water - LIX 84 liquid-liquid system ${ }^{[3]}$ with an absolute average relative error (AARE) of 5.76\%. The Average Absolute Relative Errors (AARE) caused by fitting the experimental data for water - Alamine ${ }^{\circledR} 336$ system into the original correlation ${ }^{[3]}$ was found to be $48.65 \%$. In this study, all the experimental data collected for the two types of internals and operations (aqueous continuous or organic continuous) were fitted to equation 13 (see Figure 7) with correlations constants $\mathrm{k}_{1}$ and $\mathrm{k}_{2}$ (in Table 4) dependent on the operating regime (mixer-settler region at pulsation intensity of $0 \sim 0.015 \mathrm{~m} / \mathrm{s}$; transition and emulsion region at pulsation intensity of $0.015 \sim 0.03 \mathrm{~m} / \mathrm{s}$ ). $\mathrm{k}_{1}$ and $\mathrm{k}_{2}$ here in Table 4 are also applicable to predict the holdup for previous system ${ }^{[3]}$ and resulting in AAREs of $14.58 \%$ and $7.40 \%$ for Tenova kinetics internals and standard disc and doughnut internals, respectively.

$$
x_{d}=k_{1} \exp \left[k_{2}\left|A f-(A f)_{m}\right|\left(\frac{v_{d}^{4} \rho_{c}}{g \gamma}\right)^{0.31}\left(\frac{v_{c}+v_{d}}{v_{d}}\right)^{0.32}\left(\frac{\Delta \rho}{\rho_{c}}\right)^{-0.98}\left(\frac{\mu_{d}}{\mu_{c}}\right)^{0.18}\right.
$$

On this basis equation 13 can be used to predict the dispersed phase holdup in pulsed columns fitted with both standard disc and doughnut internals and TPC-KIs operating with either aqueous continuous or organic continuous. The overall AARE between the experimental data and correlation results for the three operating regimes and two different liquid-liquid systems is $15.56 \%$. Hence, the dispersed phase holdup for standard disc and doughnut internals and Tenova kinetics internals are predictable for both water - Alamine® 336 and water - LIX 84 systems.

Table 4 Regressed parameters for the correlation of dispersed phase holdup shown by equation (13)

\begin{tabular}{|c|c|c|c|c|c|}
\hline Internals & Operation & Operating regime & $\mathbf{k}_{1}$ & $\mathbf{k}_{2}$ & AARE \\
\hline \multirow{3}{*}{$\begin{array}{l}\text { Standard disc and } \\
\text { doughnut internals }\end{array}$} & \multirow{3}{*}{ Organic continuous system } & mixer-settler & 7.65 & 77.30 & \multirow{3}{*}{$15.45 \%$} \\
\hline & & & & & \\
\hline & & transition \& emulsion & 6.34 & 39.17 & \\
\hline \multirow{5}{*}{ Tenova kinetics } & \multirow{3}{*}{ Organic continuous system } & mixer-settler & 7.71 & 6.49 & \multirow{3}{*}{$21.67 \%$} \\
\hline & & & & & \\
\hline & & transition \& emulsion & 6.11 & 21.97 & \\
\hline & Aqueous continuous & mixer-settler & 3.75 & 91.48 & \multirow{2}{*}{$12.03 \%$} \\
\hline & system & transition \& emulsion & 1.64 & 43.80 & \\
\hline
\end{tabular}




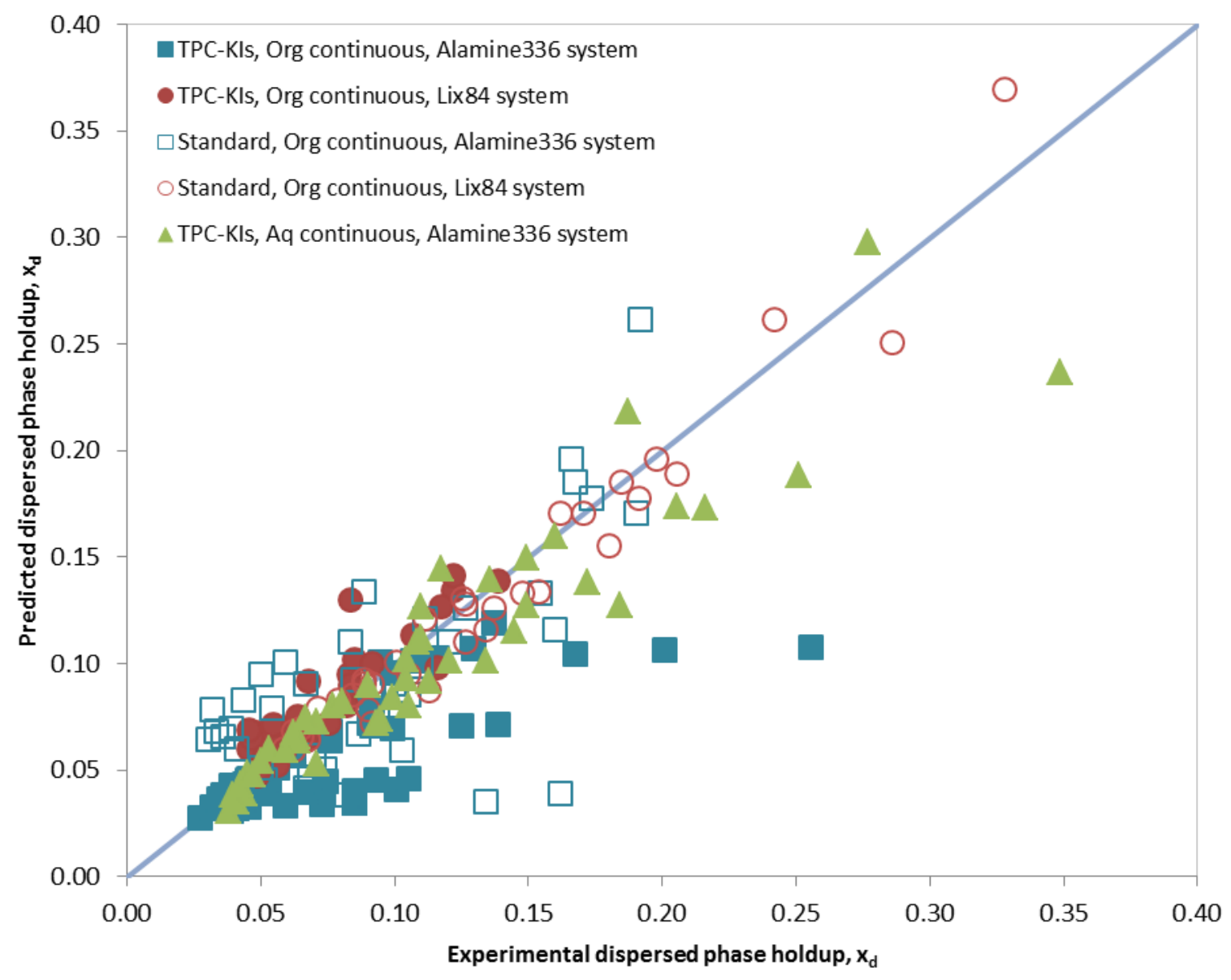

Figure 7. Comparison of the experimental dispersed phase holdup and predicted holdup with Eq. 13

\subsection{Drop size - Sauter mean diameter $d_{32}$}

Another significant hydrodynamic parameter used to determine the interfacial area between two immiscible phases is dispersed phase drop size which can be represented by the Sauter mean diameter $\left(d_{32}\right)$. Up to 300 individual droplet sizes under each particular Af, $\mathrm{V}_{\mathrm{c}}$ and $\mathrm{V}_{\mathrm{d}}$ were recorded under a range of pulsation intensities and phase velocities using photographs taken in the Perspex cubical viewing boxes located in the middle of the column (Figure 8). The diameters of dispersed phase droplets were measured manually via Measurer 1.2 software, using the known distance between each internal plate as the reference scale. All the Sauter mean diameter data were obtained at the same operating conditions as the dispersed phase holdup. Results are presented in Figure 9 and Figure 10. 


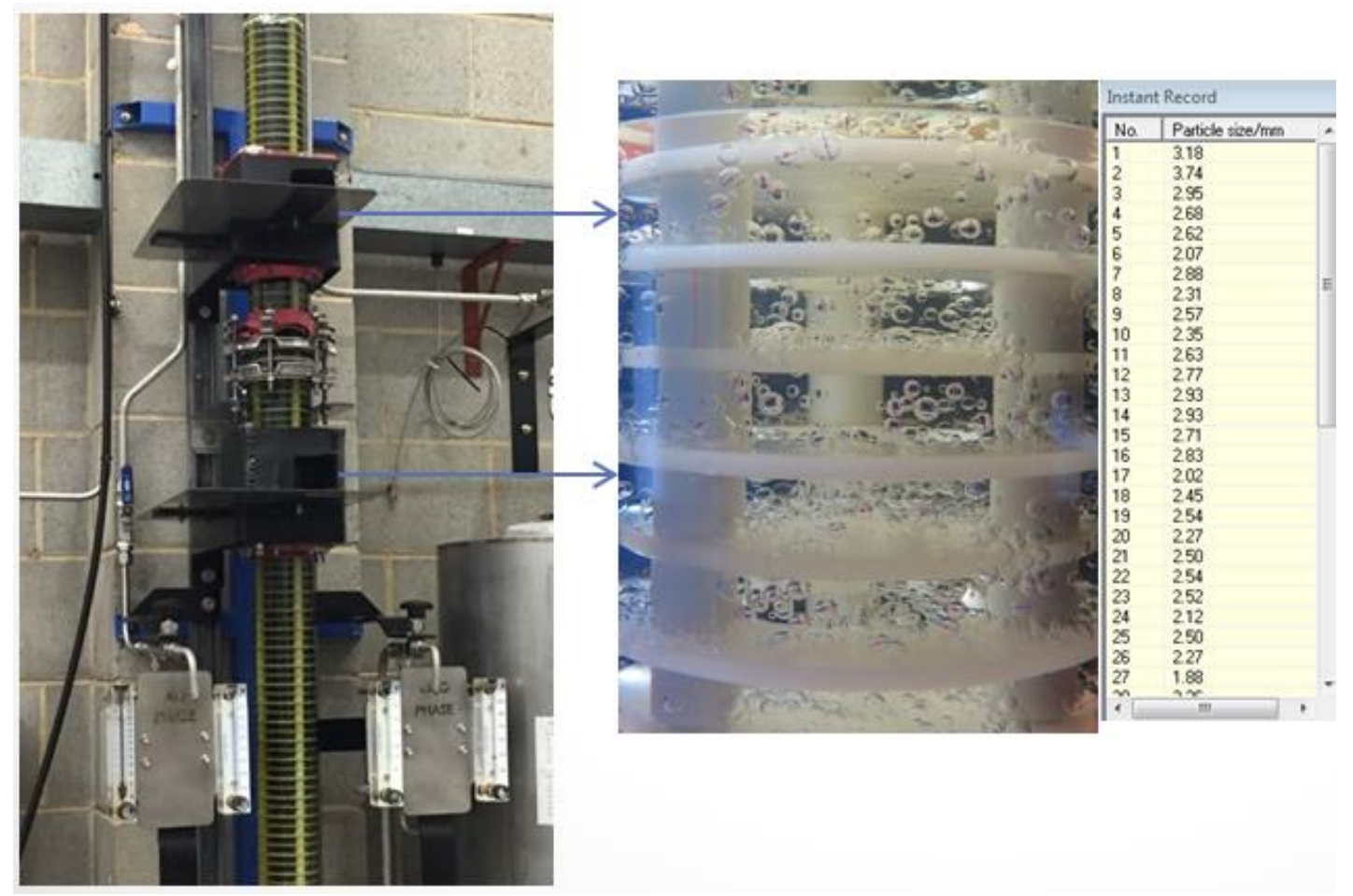

Figure 8. Apparatus and software for measurement of dispersed phase droplets

In Figure 9, the Sauter mean diameter of the dispersed phase droplets using the TPC-KIs with aqueous continuous (open points) and organic continuous (closed points) is shown under various pulsation intensity and phase velocities. It is clearly shown that $\mathrm{d}_{32}$ decreases as pulsation intensity increases from $0.005 \mathrm{~m} / \mathrm{s}$ up to $0.03 \mathrm{~m} / \mathrm{s}$. At low pulsing rate $(\mathrm{Af} \leqslant 0.015 \mathrm{~m} / \mathrm{s}), \mathrm{d}_{32}$ experimental points for aqueous continuous system do not vary much with variation in $\mathrm{A} / \mathrm{O}$ ratios compared to that with organic continuous system. At high pulsing rate conditions (Af $\geqslant$ $0.02 \mathrm{~m} / \mathrm{s}$ ), the Sauter mean diameters for both the aqueous continuous and organic continuous systems are very similar due to excess mechanical energy from the pulsing unit and less impact from the wettability of the internals. 


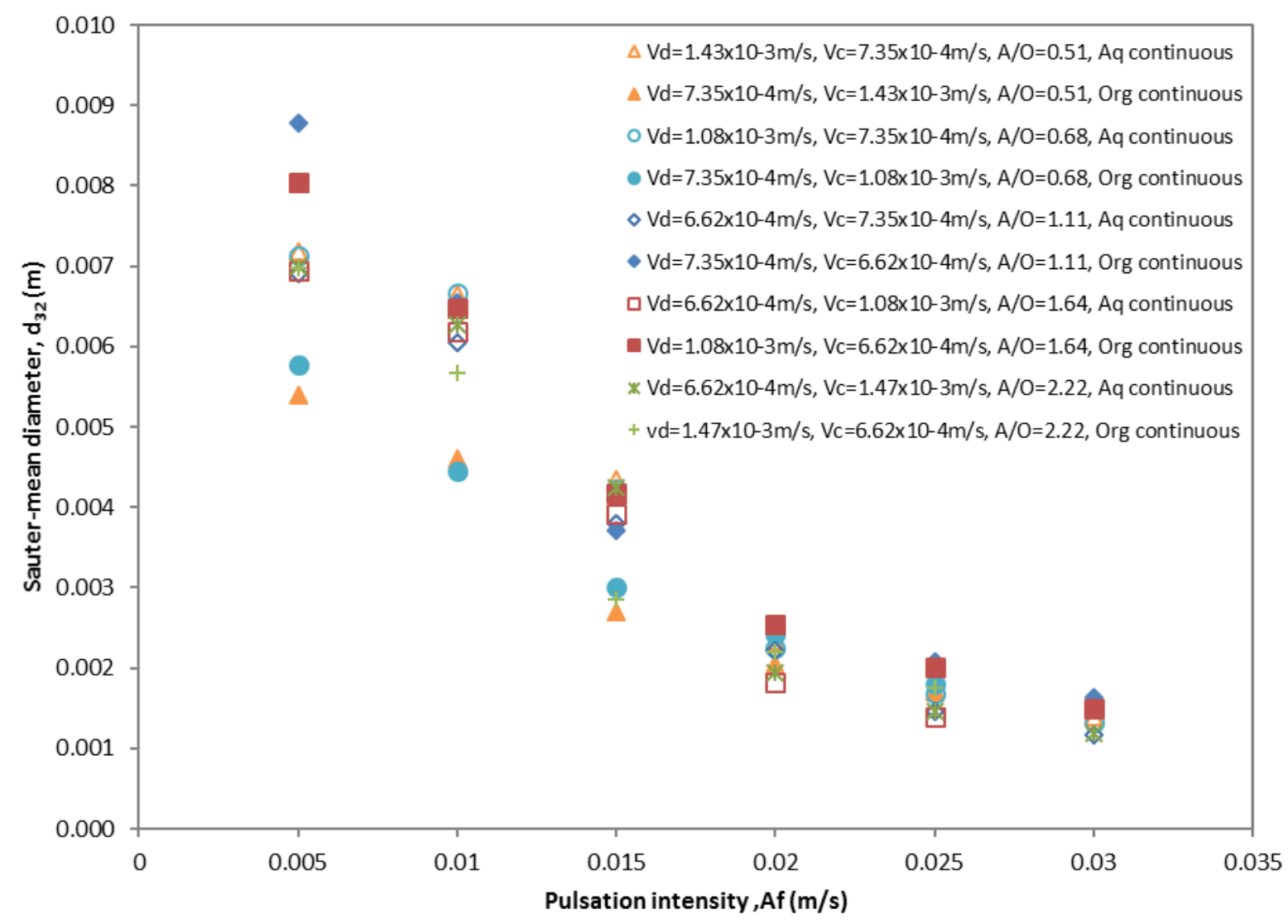

Figure 9. Effect of pulsation intensity on the Sauter mean diameter $\mathrm{d}_{32}$ with different aqueous to organic phase ratio

In this water - Alamine 336 system (faster kinetics liquid-liquid system compared to water - LIX 84 system), the Sauter mean diameters $d_{32}$ for both internals decrease with higher pulsation intensity and approaches a minimum value of $\sim 0.0015 \mathrm{~m}$ (see Figure 10). It is compatible with results observed in the previous study ${ }^{[3]}$ of the pulsed column with standard disc and doughnut internals and TPC-KIs by using water - Lix 84 liquid-liquid system.The effect of continuous phase velocity and dispersed phase velocity on $\mathrm{d}_{32}$ with standard disc and doughnut internals was found to be small. The experimental data for different A/O ratios for TPC-KIs were scattered over a wider range of $\mathrm{d}_{32}$, especially at low pulsing rates. Therefore it may be concluded that the inner structure and surface properties of the column internals has a larger impact on the dimensions of the dispersed phase droplets at low pulsation rates. 


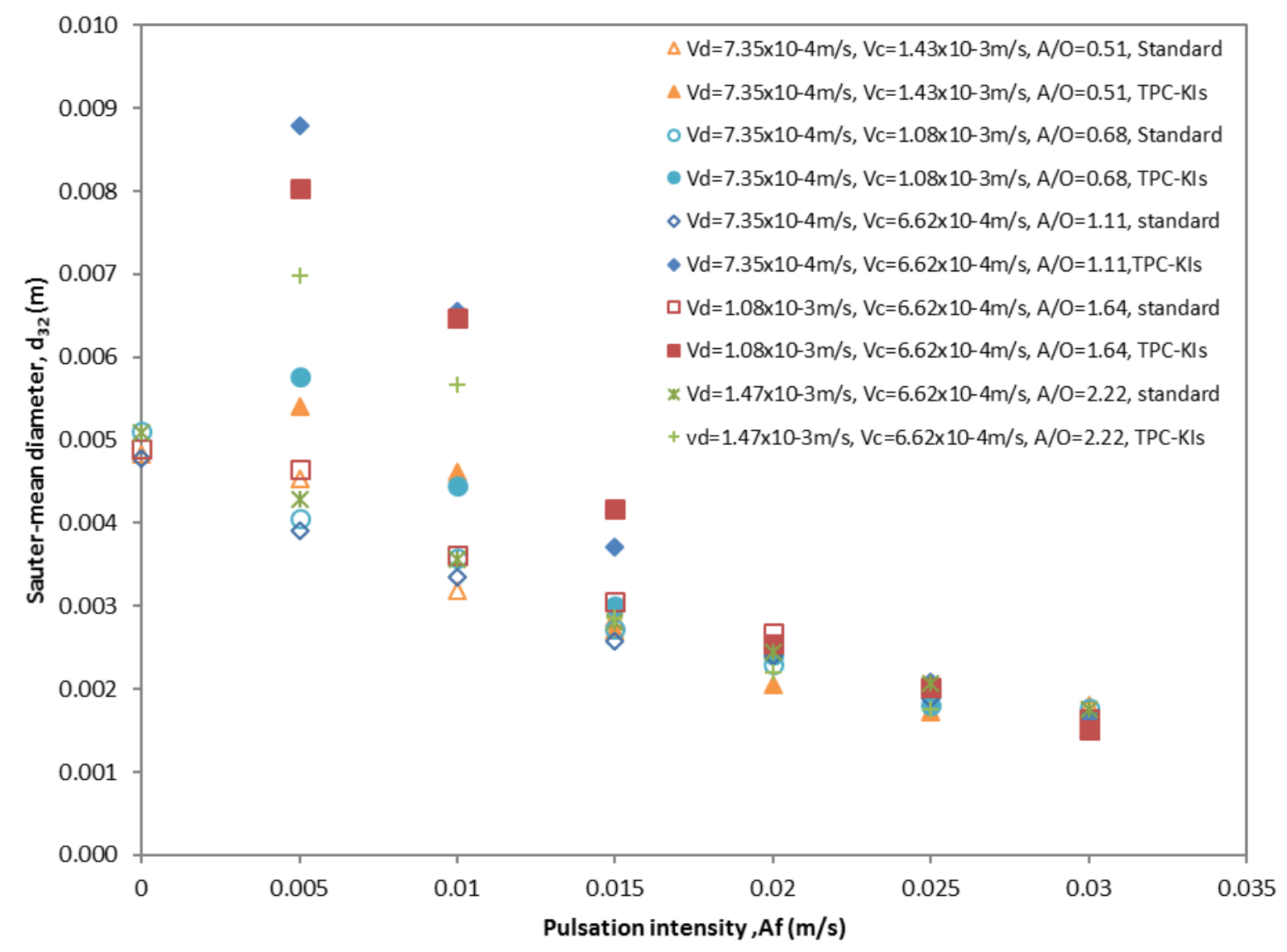

Figure 10. Effect of pulsation intensity on the Sauter mean diameter $\mathrm{d}_{32}$ with different aqueous to organic phase ratio

\subsection{Prediction of Sauter mean diameter and cumulative volume distribution}

The original correlation ${ }^{[3]}$ in literature did not fit both liquid-liquid systems, and the average absolute relative error is $19.40 \%$ for water - Alamine 336 system. Therefore, an advanced empirical correlation based on the equation developed by van Deldan et al. ${ }^{[12,13]}$ is used (see equation 14) with refitted parameters $C_{1}$ and $C_{2}$ shown in Table 5.

$$
d_{32}=C_{1} \varepsilon^{0.3}\left(\frac{\gamma}{\Delta \rho g}\right)^{0.5}\left(h \frac{\sqrt{\rho_{*} g}}{\gamma_{*}}\right)^{0.18}\left(\frac{\mu_{d} g^{0.25}}{\rho_{*}^{0.25} \gamma_{*}^{0.75}}\right)^{0.14}\left(\frac{\gamma}{\gamma_{*}}\right)^{0.06}\left[C_{2}+\exp \left\{(-2.59) \times \frac{A f}{\varepsilon\left(\frac{\gamma_{*} g}{\rho_{*}}\right)^{0.25}}\right\}\right]\left(\frac{v_{d}}{v_{c}}\right)^{0.05}
$$

$\underline{\text { Table } 5}$ Refitted constants for the correlation of Sauter mean diameter $\mathbf{d}_{32}$

$\begin{array}{lllll}\text { Constants } & \text { Operation } & \mathrm{C}_{1} & \mathrm{C}_{2} & \text { AARE }\end{array}$




\begin{tabular}{ccccc}
\hline $\begin{array}{c}\text { Standard disc and } \\
\text { doughnut internals }\end{array}$ & Organic continuous system & 0.0105 & 0.2368 & $9.44 \%$ \\
Tenova kinetics & Organic continuous system & 0.0243 & 0.0215 & $10.46 \%$ \\
internals & Aqueous continuous system & 0.02 & 0 & $11.30 \%$ \\
\hline
\end{tabular}

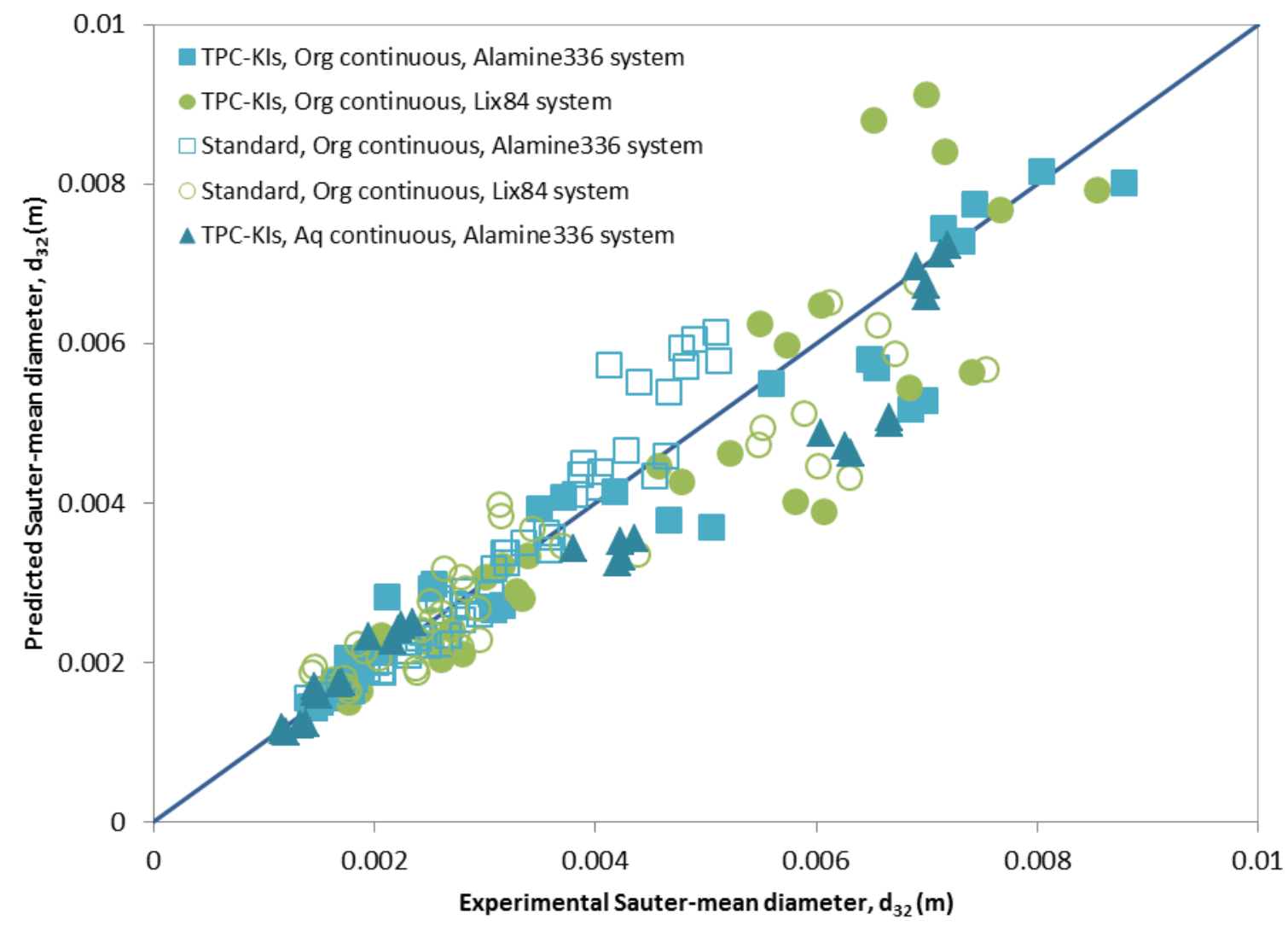

Figure 11. Comparison between the experimental Sauter mean diameter and predicted data

The correlation is well predicted the Sauter mean diameter (Figure 11) and the AARE of refitted constants are 9.44\% and $10.46 \%$ for the standard disc and doughnut internals and the Tenova kinetics internals, and $11.30 \%$ AARE for aqueous continuous system with TPC-KIs. Additionally, equation 14 can also be applied for the prediction of the dispersed phase Sauter mean diameter for the water-Lix 84 system $^{[3]}$. This results in AARE of $12.19 \%$ and $13.80 \%$ for TPC-KIs and standard disc and doughnut internals, respectively.

The droplet distribution is also studied by applying the Weibull distribution equation (equation 15). The parameters $(a, b)$ of the cumulative distribution function is summarised in Table 6 and Figure 15. 


$$
F\left(d_{i} \mid \mathrm{a}, b\right)=1-e^{-\left(\frac{d_{i}}{b}\right)^{\mathrm{a}}}
$$

$\underline{\text { Table } 6}$ Regressed parameters a and b for Equation 15

\begin{tabular}{ccccc}
\hline Internals & Operation & Operating intensity $(\mathbf{m} / \mathbf{s})$ & $\mathbf{a}$ & $\mathbf{b}$ \\
\hline \multirow{2}{*}{ Standard disc and doughnut internals } & Organic continuous & 0.01 & 6.07 & 3.44 \\
& & 0.02 & 8.24 & 2.48 \\
Tenova kinetics internals & Organic continuous & 0.01 & 5.83 & 6.55 \\
& & 0.02 & 2.53 \\
& Aqueous continuous & 0.01 & 6.88 & 6.08 \\
& & 0.02 & 4.05 & 2.23 \\
\hline
\end{tabular}

Under higher pulsing rates $(\mathrm{Af}=0.02 \mathrm{~m} / \mathrm{s})$, a smaller distribution of droplet's diameter is evident. The prediction of the cumulative drop distribution in Figure 12 shows that the predicted values fit the experimental data well. Additionally, the cumulative drop distributions for standard disc and doughnut internals are narrowed compared to TPC-KIs with either aqueous continuous system or organic continuous system. Similar trends were seen in the previous investigations with the LIX 84 in Shellsol 2046 system $^{[3]}$. 


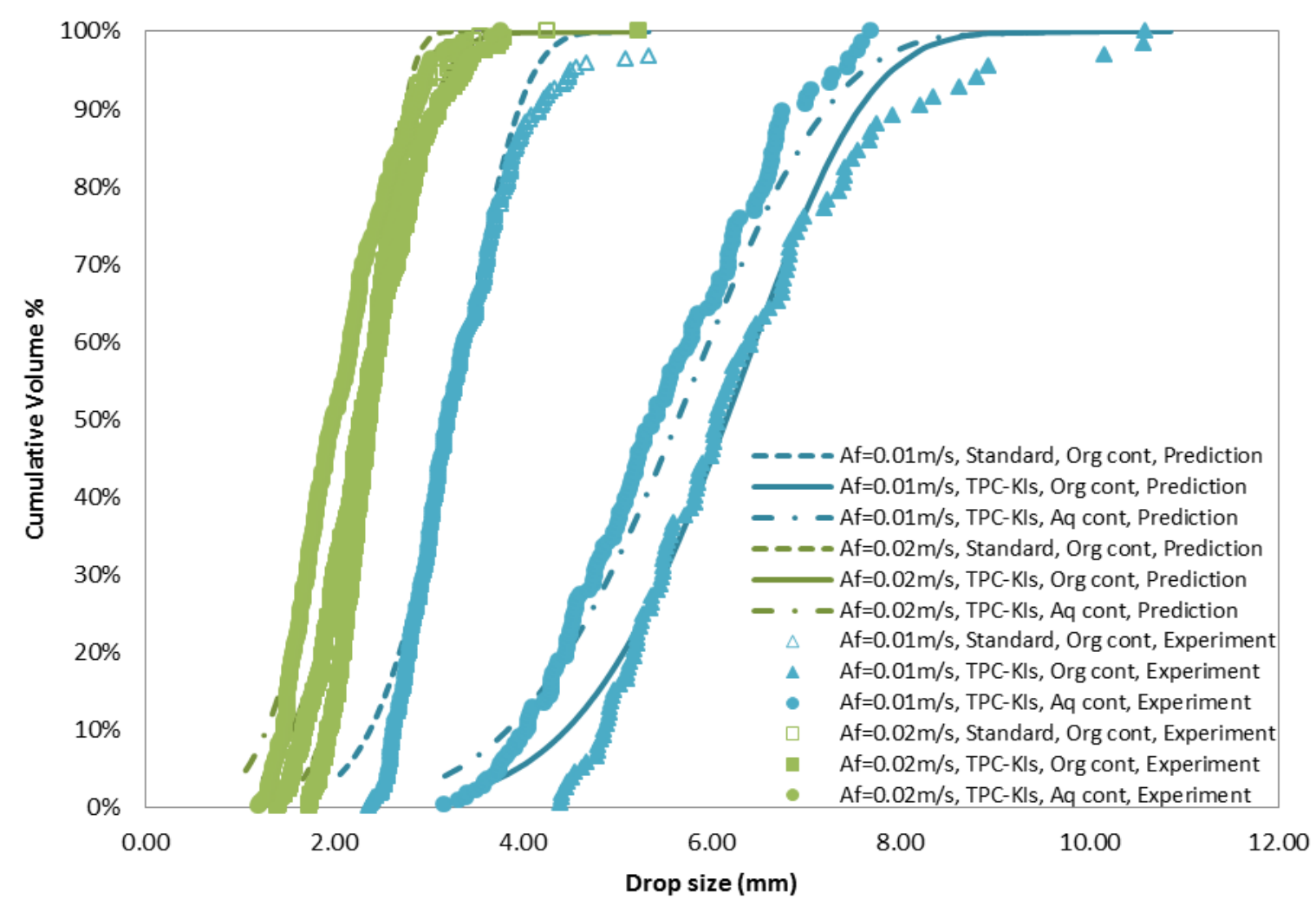

Figure 12. Prediction of drop size cumulative volume distribution with the cumulative probability function

\section{Conclusions}

1. Slightly higher dispersed phase holdup can be achieved with standard disc and doughnut internals compared with Tenova Pulsed Column - Kinetics Internals (TPC-KIs).

2. Due to the inner structure and surface property, the dispersed phase droplet diameters were scattered across a wide range at low pulsing intensity with the TPC-KIs. The internal edge and wettability of internal surface is key factor for the dispersed phase droplets formation. The Sauter mean diameter is likely independent of operating conditions at pulsation intensity higher than $0.02 \mathrm{~m} / \mathrm{s}$.

3. Correlations of both dispersed phase holdup and Sauter mean diameter for both the Tenova Pulsed Column - Kinetics Internals and the standard disc and doughnut internals and two different liquid-liquid systems are presented with the overall absolute average relative error of $15.56 \%$ and $11.44 \%$, respectively. The dispersed phase holdup and Sauter mean diameter are predictable for standard disc and doughnut internals and TPC-KIs.

\section{Acknowledgements}


The authors would like to acknowledge the funding provide by the Australian Research Council through Linkage grant LP130100305 and BHP Billiton, Olympic Dam, for this project, and would also like to thank the Particulate Fluids Processing Centre for the resources provided for this project.

\section{Nomenclature}

a interfacial area, $\mathrm{m}^{2}$

A pulsation amplitude, $\mathrm{m}$

$\mathrm{d}_{32} \quad$ Sauter-mean drop diameter, $\mathrm{m}$

f pulsation frequency, $\mathrm{Hz}$

g gravity acceleration, $\mathrm{m} / \mathrm{s}^{2}$

h column height, $\mathrm{m}$

A/O flow ratio, viz velocity ratio of dispersed phase to continuous phase, dimensionless

$\mathrm{v}_{\mathrm{d}} / \mathrm{v}_{\mathrm{c}} \quad$ dispersed phase velocity/continuous phase velocity, $\mathrm{m} / \mathrm{s}$

$\mathrm{X}_{\mathrm{d}} \quad$ volume fraction holdup of dispersed phase, dimensionless

$\varepsilon \quad$ the fractional free area, dimensionless

$\epsilon \quad$ drop distortion parameter, dimensionless

$\gamma \quad$ interfacial tension, $\mathrm{N} / \mathrm{m}$

$\mu_{\mathrm{d}} / \mu_{\mathrm{c}} \quad$ viscosity of dispersed phase/continuous phase, $\mathrm{Pa} \cdot \mathrm{s}$

$\rho_{\mathrm{d}} / \rho_{\mathrm{c}} \quad$ density of dispersed phase/continuous phase, $\mathrm{kg} / \mathrm{m}^{3[3]}$

$\Delta \rho \quad$ density difference between phases, $\mathrm{kg} / \mathrm{m}^{3}$

$\psi \quad$ mechanical power dissipation per unit mass, $\mathrm{W} / \mathrm{kg}$

Subscripts or superscripts

c continuous phase

d dispersed phase

\section{References}

[1] Technologies, T.A., Tenova Pulsed Columns, in brochure. 2014, Tenova Advanced Technologies: http://www.takraf.tenova.com/fileadmin/user_upload/pages/About_us/Brochure_Downloads/TAT_Bro chures/TAT_Brochure_Tenova_Pulsed_Columns.pdf.

[2] Wang, Y., et al., Dispersed-Phase Holdup and Characteristic Velocity in a Pulsed and Nonpulsed Diskand-Doughnut Solvent Extraction Column. Industrial \& Engineering Chemistry Research, 2016. 55(3): p. 714-721.

[3] Li, W., et al., Comparison of the Hydrodynamic Performance of Pulsed Solvent Extraction Columns with Tenova Pulsed Column Kinetics Internals and Standard Disc and Doughnut Internals for Copper Extraction Using the LIX 84 System. Solvent Extraction and Ion Exchange, 2017. 35(5): p. 303-320. 
[4] Lewis, W. and W. Whitman, The two-film theory of gas absorption. Ind. Eng. Chem, 1924. 16: p. 1215-1239.

[5] Gräbin, T., Influence of plate wettability on the performance of a pulsed disc and doughnut column. 2015.

[6] Griffith, W.L., G. Jasny, and H. Tupper, The extraction of cobalt from nickel in a pulse column (thesis). 1952, Massachusetts Inst. of Tech.

[7] Miyauchi, T. and H. Oya, Longitudinal dispersion in pulsed perforated - plate columns. AIChE Journal, 1965. 11(3): p. 395-402.

[8] Kumar, A. and S. Hartland, Prediction of dispersed-phase holdup and flooding velocities in Karr reciprocating-plate extraction columns. Industrial \& engineering chemistry research, 1988. 27(1): p. 131-138.

[9] Hinze, J., Fundamentals of the hydrodynamic mechanism of splitting in dispersion processes. AIChE Journal, 1955. 1(3): p. 289-295.

[10] Shinnar, R. and J.M. Church, Statistical theories of turbulence in predicting particle size in agitated dispersions. Industrial \& Engineering Chemistry, 1960. 52(3): p. 253-256.

[11] Kumar, A. and S. Hartland, Unified Correlations for the Prediction of Drop Size in Liquid- Liquid Extraction Columns. Industrial \& engineering chemistry research, 1996. 35(8): p. 2682-2695.

[12] Van Delden, M., N. Kuipers, and A. De Haan, Extraction of caprolactam with toluene in a pulsed disc and doughnut column-Part I: Recommendation of a model for hydraulic characteristics. Solvent extraction and ion exchange, 2006. 24(4): p. 499-517.

[13] Van Delden, M., et al., Extraction of caprolactam with toluene in a pulsed disc and doughnut columnpart II: experimental evaluation of the hydraulic characteristics. Solvent extraction and ion exchange, 2006. 24(4): p. 519-538.

[14] Torab-Mostaedi, M., A. Ghaemi, and M. Asadollahzadeh, Flooding and drop size in a pulsed disc and doughnut extraction column. Chemical Engineering Research and Design, 2011. 89(12): p. 2742-2751.

[15] Wang, Y., et al., Prediction of drop size in a pulsed and non-pulsed disc and doughnut solvent extraction column. Chemical Engineering Research and Design, 2016. 109: p. 667-674.

\section{Supporting materials:}

Table S1. Experimental holdup and predicted value for

Tenova kinetics internals at organic continuous with water-Alamine 336 system

\begin{tabular}{|c|c|c|c|c|c|c|}
\hline No. & $\mathbf{A} / \mathbf{O}$ & $\operatorname{Af}(\mathrm{m} / \mathrm{s})$ & $\mathbf{X}_{\text {d_exp }}$ & $\mathbf{X}_{\text {d_pred }}$ & d32_exp $(m)$ & d32_pred $(\mathrm{m})$ \\
\hline 1 & 1.11 & 0 & 0.0852 & 0.0343 & NA & NA \\
\hline 2 & 0.68 & 0 & 0.1005 & 0.0411 & NA & NA \\
\hline 3 & 0.51 & 0 & 0.1050 & 0.0461 & NA & NA \\
\hline 4 & 1.64 & 0 & 0.1385 & 0.0716 & NA & NA \\
\hline 5 & 2.22 & 0 & 0.2557 & 0.1079 & NA & NA \\
\hline 6 & 1.11 & 0.005 & 0.0594 & 0.0332 & 0.0074 & 0.0077 \\
\hline 7 & 0.68 & 0.005 & 0.0670 & 0.0398 & 0.0071 & 0.0074 \\
\hline 8 & 0.51 & 0.005 & 0.0746 & 0.0446 & 0.0073 & 0.0073 \\
\hline 9 & 1.64 & 0.005 & 0.0989 & 0.0693 & 0.0088 & 0.0080 \\
\hline 10 & 2.22 & 0.005 & 0.1674 & 0.1045 & 0.0080 & 0.0082 \\
\hline 11 & 1.11 & 0.01 & 0.0411 & 0.0322 & 0.0056 & 0.0055 \\
\hline 12 & 0.68 & 0.01 & 0.0449 & 0.0385 & 0.0070 & 0.0053 \\
\hline 13 & 0.51 & 0.01 & 0.0441 & 0.0432 & 0.0069 & 0.0052 \\
\hline 14 & 1.64 & 0.01 & 0.0731 & 0.0671 & 0.0065 & 0.0057 \\
\hline 15 & 2.22 & 0.01 & 0.1065 & 0.1011 & 0.0065 & 0.0058 \\
\hline
\end{tabular}




\begin{tabular}{|l|c|c|c|c|c|c|}
\hline $\mathbf{1 6}$ & 1.11 & 0.015 & 0.0274 & 0.0273 & 0.0035 & 0.0039 \\
\hline $\mathbf{1 7}$ & 0.68 & 0.015 & 0.0320 & 0.0327 & 0.0047 & 0.0038 \\
\hline $\mathbf{1 8}$ & 0.51 & 0.015 & 0.0342 & 0.0367 & 0.0051 & 0.0037 \\
\hline $\mathbf{1 9}$ & 1.64 & 0.015 & 0.0624 & 0.0570 & 0.0037 & 0.0041 \\
\hline $\mathbf{2 0}$ & 2.22 & 0.015 & 0.0868 & 0.0858 & 0.0042 & 0.0041 \\
\hline $\mathbf{2 1}$ & 1.11 & 0.02 & 0.0388 & 0.0305 & 0.0021 & 0.0028 \\
\hline $\mathbf{2 2}$ & 0.68 & 0.02 & 0.0434 & 0.0365 & 0.0032 & 0.0027 \\
\hline $\mathbf{2 3}$ & 0.51 & 0.02 & 0.0449 & 0.0409 & 0.0031 & 0.0027 \\
\hline $\mathbf{2 4}$ & 1.64 & 0.02 & 0.0761 & 0.0636 & 0.0025 & 0.0029 \\
\hline $\mathbf{2 5}$ & 2.22 & 0.02 & 0.0989 & 0.0958 & 0.0025 & 0.0030 \\
\hline $\mathbf{2 6}$ & 1.11 & 0.025 & 0.0411 & 0.0340 & 0.0018 & 0.0021 \\
\hline $\mathbf{2 7}$ & 0.68 & 0.025 & 0.0434 & 0.0407 & 0.0018 & 0.0020 \\
\hline $\mathbf{2 8}$ & 0.51 & 0.025 & 0.0457 & 0.0457 & 0.0018 & 0.0019 \\
\hline $\mathbf{2 9}$ & 1.64 & 0.025 & 0.0913 & 0.0710 & 0.0021 & 0.0021 \\
\hline $\mathbf{3 0}$ & 2.22 & 0.025 & 0.1294 & 0.1069 & 0.0020 & 0.0022 \\
\hline $\mathbf{3 1}$ & 1.11 & 0.03 & 0.0411 & 0.0380 & 0.0015 & 0.0015 \\
\hline $\mathbf{3 2}$ & 0.68 & 0.03 & 0.0449 & 0.0454 & 0.0014 & 0.0015 \\
\hline $\mathbf{3 3}$ & 0.51 & 0.03 & 0.0563 & 0.0510 & 0.0015 & 0.0014 \\
\hline $\mathbf{3 4}$ & 1.64 & 0.03 & 0.0913 & 0.0792 & 0.0016 & 0.0016 \\
\hline $\mathbf{3 5}$ & 2.22 & 0.03 & 0.1370 & 0.1194 & 0.0015 & 0.0016 \\
\hline
\end{tabular}

Table S2. Experimental holdup and predicted value for standard disc and doughnut internals at organic continuous with water-Alamine 336 system

\begin{tabular}{|c|c|c|c|c|c|c|}
\hline No. & $\mathbf{A} / \mathbf{O}$ & $\mathbf{A f}(\mathbf{m} / \mathbf{s})$ & $\mathbf{\mathbf { x } _ { \text { d_exp } }}$ & $\mathbf{\mathbf { d } _ { \mathbf { d } } \mathbf { p r e d }}$ & $\mathbf{d}$ 32_exp $(\mathbf{m})$ & $\mathbf{d}$ 32_pred $(\mathbf{m})$ \\
\hline $\mathbf{1}$ & 1.11 & 0 & 0.1903 & 0.1705 & 0.0048 & 0.0059 \\
\hline $\mathbf{2}$ & 0.68 & 0 & 0.1674 & 0.1855 & 0.0051 & 0.0058 \\
\hline $\mathbf{3}$ & 0.51 & 0 & 0.1659 & 0.1962 & 0.0048 & 0.0057 \\
\hline $\mathbf{4}$ & 1.64 & 0 & 0.1918 & 0.2617 & 0.0049 & 0.0061 \\
\hline $\mathbf{5}$ & 2.22 & 0 & 0.2100 & 0.3693 & 0.0051 & 0.0061 \\
\hline $\mathbf{6}$ & 1.11 & 0.005 & 0.1598 & 0.1158 & 0.0039 & 0.0045 \\
\hline $\mathbf{7}$ & 0.68 & 0.005 & 0.1263 & 0.1260 & 0.0041 & 0.0044 \\
\hline $\mathbf{8}$ & 0.51 & 0.005 & 0.1545 & 0.1333 & 0.0045 & 0.0043 \\
\hline $\mathbf{9}$ & 1.64 & 0.005 & 0.1735 & 0.1778 & 0.0046 & 0.0046 \\
\hline $\mathbf{1 0}$ & 2.22 & 0.005 & 0.1933 & 0.2509 & 0.0043 & 0.0047 \\
\hline $\mathbf{1 1}$ & 1.11 & 0.01 & 0.1050 & 0.0787 & 0.0033 & 0.0035 \\
\hline $\mathbf{1 2}$ & 0.68 & 0.01 & 0.0997 & 0.0856 & 0.0036 & 0.0034 \\
\hline $\mathbf{1 3}$ & 0.51 & 0.01 & 0.1111 & 0.0906 & 0.0032 & 0.0034 \\
\hline $\mathbf{1 4}$ & 1.64 & 0.01 & 0.1339 & 0.1208 & 0.0036 & 0.0036 \\
\hline $\mathbf{1 5}$ & 2.22 & 0.01 & 0.1621 & 0.1705 & 0.0036 & 0.0036 \\
\hline & & & & & & \\
\hline
\end{tabular}




\begin{tabular}{|l|l|l|l|l|l|l|}
\hline $\mathbf{1 6}$ & 1.11 & 0.015 & 0.0845 & 0.0602 & 0.0026 & 0.0028 \\
\hline $\mathbf{1 7}$ & 0.68 & 0.015 & 0.0852 & 0.0656 & 0.0027 & 0.0027 \\
\hline $\mathbf{1 8}$ & 0.51 & 0.015 & 0.0822 & 0.0693 & 0.0029 & 0.0027 \\
\hline $\mathbf{1 9}$ & 1.64 & 0.015 & 0.1027 & 0.0925 & 0.0031 & 0.0028 \\
\hline $\mathbf{2 0}$ & 2.22 & 0.015 & 0.1202 & 0.1305 & 0.0028 & 0.0029 \\
\hline $\mathbf{2 1}$ & 1.11 & 0.02 & 0.0670 & 0.0590 & 0.0024 & 0.0023 \\
\hline $\mathbf{2 2}$ & 0.68 & 0.02 & 0.0670 & 0.0642 & 0.0023 & 0.0022 \\
\hline $\mathbf{2 3}$ & 0.51 & 0.02 & 0.0685 & 0.0679 & 0.0025 & 0.0022 \\
\hline $\mathbf{2 4}$ & 1.64 & 0.02 & 0.0906 & 0.0906 & 0.0027 & 0.0023 \\
\hline $\mathbf{2 5}$ & 2.22 & 0.02 & 0.1172 & 0.1278 & 0.0024 & 0.0024 \\
\hline $\mathbf{2 6}$ & 1.11 & 0.025 & 0.0837 & 0.0717 & 0.0019 & 0.0020 \\
\hline $\mathbf{2 7}$ & 0.68 & 0.025 & 0.0738 & 0.0781 & 0.0019 & 0.0019 \\
\hline $\mathbf{2 8}$ & 0.51 & 0.025 & 0.0700 & 0.0826 & 0.0021 & 0.0019 \\
\hline $\mathbf{2 9}$ & 1.64 & 0.025 & 0.1005 & 0.1102 & 0.0020 & 0.0020 \\
\hline $\mathbf{3 0}$ & 2.22 & 0.025 & 0.1218 & 0.1554 & 0.0021 & 0.0020 \\
\hline $\mathbf{3 1}$ & 1.11 & 0.03 & 0.0883 & 0.0873 & 0.0017 & 0.0017 \\
\hline $\mathbf{3 2}$ & 0.68 & 0.03 & 0.0807 & 0.0950 & 0.0018 & 0.0017 \\
\hline $\mathbf{3 3}$ & 0.51 & 0.03 & 0.0791 & 0.1005 & 0.0018 & 0.0016 \\
\hline $\mathbf{3 4}$ & 1.64 & 0.03 & 0.1210 & 0.1340 & 0.0016 & 0.0017 \\
\hline $\mathbf{3 5}$ & 2.22 & 0.03 & 0.1568 & 0.1890 & 0.0018 & 0.0018 \\
\hline & & & & & & \\
\hline
\end{tabular}

Table S3. Experimental holdup and predicted value for

Tenova kinetics internals at aqueous continuous with water-Alamine 336 system

\begin{tabular}{|c|c|c|c|c|c|c|}
\hline No. & $\mathbf{A} / \mathbf{O}$ & $\mathbf{A f}(\mathbf{m} / \mathbf{s})$ & $\mathbf{x}_{\text {d_exp }}$ & $\mathbf{x}_{\text {d_pred }}$ & $\mathbf{d}$ 32_exp \\
\hline $\mathbf{1}$ & 1.11 & 0 & 0.1096 & 0.1270 & NA & d32_pred $(\mathbf{m})$ \\
\hline $\mathbf{2}$ & 1.64 & 0 & 0.1172 & 0.1446 & NA & NA \\
\hline $\mathbf{3}$ & 2.22 & 0 & 0.1598 & 0.1598 & NA & NA \\
\hline $\mathbf{4}$ & 0.68 & 0 & 0.1872 & 0.2184 & NA & NA \\
\hline $\mathbf{5}$ & 0.51 & 0 & 0.2770 & 0.2976 & NA & NA \\
\hline $\mathbf{6}$ & 1.11 & 0.005 & 0.1202 & 0.1010 & 0.0069 & 0.0070 \\
\hline $\mathbf{7}$ & 1.64 & 0.005 & 0.1446 & 0.1150 & 0.0070 & 0.0067 \\
\hline $\mathbf{8}$ & 2.22 & 0.005 & 0.1842 & 0.1271 & 0.0070 & 0.0066 \\
\hline $\mathbf{9}$ & 0.68 & 0.005 & 0.2055 & 0.1737 & 0.0071 & 0.0071 \\
\hline $\mathbf{1 0}$ & 0.51 & 0.005 & 0.3486 & 0.2368 & 0.0072 & 0.0072 \\
\hline $\mathbf{1 1}$ & 1.11 & 0.01 & 0.1050 & 0.0804 & 0.0060 & 0.0049 \\
\hline $\mathbf{1 2}$ & 1.64 & 0.01 & 0.1126 & 0.0915 & 0.0063 & 0.0047 \\
\hline $\mathbf{1 3}$ & 2.22 & 0.01 & 0.1339 & 0.1012 & 0.0063 & 0.0046 \\
\hline $\mathbf{1 4}$ & 0.68 & 0.01 & 0.1720 & 0.1382 & 0.0067 & 0.0050 \\
\hline $\mathbf{1 5}$ & 0.51 & 0.01 & 0.2511 & 0.1884 & 0.0067 & 0.0051 \\
\hline
\end{tabular}




\begin{tabular}{|l|l|l|l|l|l|l|}
\hline $\mathbf{1 6}$ & 1.11 & 0.015 & 0.0639 & 0.0639 & 0.0038 & 0.0034 \\
\hline $\mathbf{1 7}$ & 1.64 & 0.015 & 0.0708 & 0.0728 & 0.0042 & 0.0033 \\
\hline $\mathbf{1 8}$ & 2.22 & 0.015 & 0.0769 & 0.0805 & 0.0042 & 0.0032 \\
\hline $\mathbf{1 9}$ & 0.68 & 0.015 & 0.1081 & 0.1099 & 0.0042 & 0.0035 \\
\hline $\mathbf{2 0}$ & 0.51 & 0.015 & 0.1492 & 0.1499 & 0.0044 & 0.0036 \\
\hline $\mathbf{2 1}$ & 1.11 & 0.02 & 0.0381 & 0.0308 & 0.0022 & 0.0024 \\
\hline $\mathbf{2 2}$ & 1.64 & 0.02 & 0.0411 & 0.0350 & 0.0019 & 0.0023 \\
\hline $\mathbf{2 3}$ & 2.22 & 0.02 & 0.0441 & 0.0387 & 0.0022 & 0.0023 \\
\hline $\mathbf{2 4}$ & 0.68 & 0.02 & 0.0708 & 0.0529 & 0.0023 & 0.0025 \\
\hline $\mathbf{2 5}$ & 0.51 & 0.02 & 0.0928 & 0.0721 & 0.0023 & 0.0025 \\
\hline $\mathbf{2 6}$ & 1.11 & 0.025 & 0.0396 & 0.0383 & 0.0015 & 0.0017 \\
\hline $\mathbf{2 7}$ & 1.64 & 0.025 & 0.0426 & 0.0436 & 0.0015 & 0.0016 \\
\hline $\mathbf{2 8}$ & 2.22 & 0.025 & 0.0449 & 0.0482 & 0.0015 & 0.0016 \\
\hline $\mathbf{2 9}$ & 0.68 & 0.025 & 0.0639 & 0.0659 & 0.0017 & 0.0017 \\
\hline $\mathbf{3 0}$ & 0.51 & 0.025 & 0.0898 & 0.0898 & 0.0017 & 0.0018 \\
\hline $\mathbf{3 1}$ & 1.11 & 0.03 & 0.0472 & 0.0477 & 0.0012 & 0.0012 \\
\hline $\mathbf{3 2}$ & 1.64 & 0.03 & 0.0502 & 0.0543 & 0.0012 & 0.0011 \\
\hline $\mathbf{3 3}$ & 2.22 & 0.03 & 0.0533 & 0.0600 & 0.0012 & 0.0011 \\
\hline $\mathbf{3 4}$ & 0.68 & 0.03 & 0.0807 & 0.0820 & 0.0013 & 0.0012 \\
\hline $\mathbf{3 5}$ & 0.51 & 0.03 & 0.1096 & 0.1118 & 0.0014 & 0.0012 \\
\hline & & & & & & \\
\hline
\end{tabular}

Table S4. Experimental holdup and predicted value for

Tenova kinetics internals at organic continuous with water-Lix 84 system

\begin{tabular}{|c|c|c|c|c|c|c|}
\hline No. & A/O & Af (m/s) & Xd_exp & xd_pred & d32_exp $(\mathbf{m})$ & d32_pred $(\mathbf{m})$ \\
\hline $\mathbf{1}$ & 1.11 & 0 & 0.0670 & 0.0639 & NA & NA \\
\hline $\mathbf{2}$ & 0.68 & 0 & 0.0685 & 0.0696 & NA & NA \\
\hline $\mathbf{3}$ & 0.51 & 0 & 0.0639 & 0.0736 & NA & NA \\
\hline $\mathbf{4}$ & 1.64 & 0 & 0.1157 & 0.0982 & NA & NA \\
\hline $\mathbf{5}$ & 2.22 & 0 & 0.1385 & 0.1385 & NA & NA \\
\hline $\mathbf{6}$ & 1.11 & 0.005 & 0.0556 & 0.0619 & 0.0072 & 0.0084 \\
\hline $\mathbf{7}$ & 0.68 & 0.005 & 0.0487 & 0.0674 & 0.0085 & 0.0079 \\
\hline $\mathbf{8}$ & 0.51 & 0.005 & 0.0548 & 0.0713 & 0.0077 & 0.0077 \\
\hline $\mathbf{9}$ & 1.64 & 0.005 & 0.0830 & 0.0950 & 0.0065 & 0.0088 \\
\hline $\mathbf{1 0}$ & 2.22 & 0.005 & 0.1218 & 0.1341 & 0.0070 & 0.0091 \\
\hline $\mathbf{1 1}$ & 1.11 & 0.01 & 0.0457 & 0.0599 & 0.0057 & 0.0060 \\
\hline $\mathbf{1 2}$ & 0.68 & 0.01 & 0.0464 & 0.0652 & 0.0074 & 0.0056 \\
\hline $\mathbf{1 3}$ & 0.51 & 0.01 & 0.0457 & 0.0690 & 0.0068 & 0.0054 \\
\hline $\mathbf{1 4}$ & 1.64 & 0.01 & 0.0677 & 0.0920 & 0.0055 & 0.0063 \\
\hline
\end{tabular}




\begin{tabular}{|l|l|l|l|l|l|l|}
\hline $\mathbf{1 5}$ & 2.22 & 0.01 & 0.0837 & 0.1298 & 0.0061 & 0.0065 \\
\hline $\mathbf{1 6}$ & 1.11 & 0.015 & 0.0487 & 0.0469 & 0.0048 & 0.0043 \\
\hline $\mathbf{1 7}$ & 0.68 & 0.015 & 0.0495 & 0.0511 & 0.0058 & 0.0040 \\
\hline $\mathbf{1 8}$ & 0.51 & 0.015 & 0.0540 & 0.0540 & 0.0061 & 0.0039 \\
\hline $\mathbf{1 9}$ & 1.64 & 0.015 & 0.0753 & 0.0721 & 0.0046 & 0.0045 \\
\hline $\mathbf{2 0}$ & 2.22 & 0.015 & 0.0852 & 0.1017 & 0.0052 & 0.0046 \\
\hline $\mathbf{2 1}$ & 1.11 & 0.02 & 0.0563 & 0.0524 & 0.0030 & 0.0031 \\
\hline $\mathbf{2 2}$ & 0.68 & 0.02 & 0.0518 & 0.0570 & 0.0033 & 0.0029 \\
\hline $\mathbf{2 3}$ & 0.51 & 0.02 & 0.0556 & 0.0603 & 0.0033 & 0.0028 \\
\hline $\mathbf{2 4}$ & 1.64 & 0.02 & 0.0822 & 0.0804 & 0.0032 & 0.0032 \\
\hline $\mathbf{2 5}$ & 2.22 & 0.02 & 0.1065 & 0.1135 & 0.0034 & 0.0033 \\
\hline $\mathbf{2 6}$ & 1.11 & 0.025 & 0.0586 & 0.0585 & 0.0025 & 0.0022 \\
\hline $\mathbf{2 7}$ & 0.68 & 0.025 & 0.0609 & 0.0636 & 0.0028 & 0.0021 \\
\hline $\mathbf{2 8}$ & 0.51 & 0.025 & 0.0624 & 0.0673 & 0.0026 & 0.0020 \\
\hline $\mathbf{2 9}$ & 1.64 & 0.025 & 0.0837 & 0.0898 & 0.0021 & 0.0023 \\
\hline $\mathbf{3 0}$ & 2.22 & 0.025 & 0.1172 & 0.1267 & 0.0027 & 0.0024 \\
\hline $\mathbf{3 1}$ & 1.11 & 0.03 & 0.0616 & 0.0653 & 0.0019 & 0.0016 \\
\hline $\mathbf{3 2}$ & 0.68 & 0.03 & 0.0624 & 0.0710 & 0.0018 & 0.0015 \\
\hline $\mathbf{3 3}$ & 0.51 & 0.03 & 0.0639 & 0.0751 & 0.0018 & 0.0015 \\
\hline $\mathbf{3 4}$ & 1.64 & 0.03 & 0.0913 & 0.1002 & 0.0018 & 0.0017 \\
\hline $\mathbf{3 5}$ & 2.22 & 0.03 & 0.1218 & 0.1414 & 0.0016 & 0.0018 \\
\hline & & & & & & \\
\hline
\end{tabular}

Table S5. Experimental holdup and predicted value for

Standard disc and doughnut internals at organic continuous with water-Lix 84 system

\begin{tabular}{|c|c|c|c|c|c|c|}
\hline No. & $\mathbf{A} / \mathbf{O}$ & $\mathbf{A f}(\mathbf{m} / \mathbf{s})$ & Xd_exp & Xd_pred & d32_exp $(\mathbf{m})$ & d32_pred $(\mathbf{m})$ \\
\hline $\mathbf{1}$ & 1.11 & 0 & 0.1705 & 0.1705 & 0.0066 & 0.0062 \\
\hline $\mathbf{2}$ & 0.68 & 0 & 0.1849 & 0.1855 & 0.0067 & 0.0059 \\
\hline $\mathbf{3}$ & 0.51 & 0 & 0.1979 & 0.1962 & 0.0075 & 0.0057 \\
\hline $\mathbf{4}$ & 1.64 & 0 & 0.2420 & 0.2617 & 0.0061 & 0.0065 \\
\hline $\mathbf{5}$ & 2.22 & 0 & 0.3280 & 0.3693 & 0.0069 & 0.0068 \\
\hline $\mathbf{6}$ & 1.11 & 0.005 & 0.1339 & 0.1158 & 0.0055 & 0.0047 \\
\hline $\mathbf{7}$ & 0.68 & 0.005 & 0.1370 & 0.1260 & 0.0060 & 0.0045 \\
\hline $\mathbf{8}$ & 0.51 & 0.005 & 0.1476 & 0.1333 & 0.0063 & 0.0043 \\
\hline $\mathbf{9}$ & 1.64 & 0.005 & 0.1910 & 0.1778 & 0.0055 & 0.0049 \\
\hline $\mathbf{1 0}$ & 2.22 & 0.005 & 0.2861 & 0.2509 & 0.0059 & 0.0051 \\
\hline $\mathbf{1 1}$ & 1.11 & 0.01 & 0.0715 & 0.0787 & 0.0034 & 0.0037 \\
\hline $\mathbf{1 2}$ & 0.68 & 0.01 & 0.0845 & 0.0856 & 0.0037 & 0.0035 \\
\hline $\mathbf{1 3}$ & 0.51 & 0.01 & 0.0883 & 0.0906 & 0.0044 & 0.0034 \\
\hline $\mathbf{1 4}$ & 1.64 & 0.01 & 0.1111 & 0.1208 & 0.0031 & 0.0038 \\
\hline
\end{tabular}




\begin{tabular}{|l|l|l|l|l|l|l|}
\hline $\mathbf{1 5}$ & 2.22 & 0.01 & 0.1621 & 0.1705 & 0.0031 & 0.0040 \\
\hline $\mathbf{1 6}$ & 1.11 & 0.015 & 0.0586 & 0.0602 & 0.0028 & 0.0029 \\
\hline $\mathbf{1 7}$ & 0.68 & 0.015 & 0.0654 & 0.0656 & 0.0025 & 0.0028 \\
\hline $\mathbf{1 8}$ & 0.51 & 0.015 & 0.0647 & 0.0693 & 0.0029 & 0.0027 \\
\hline $\mathbf{1 9}$ & 1.64 & 0.015 & 0.0883 & 0.0925 & 0.0028 & 0.0031 \\
\hline $\mathbf{2 0}$ & 2.22 & 0.015 & 0.1256 & 0.1305 & 0.0026 & 0.0032 \\
\hline $\mathbf{2 1}$ & 1.11 & 0.02 & 0.0624 & 0.0590 & 0.0024 & 0.0024 \\
\hline $\mathbf{2 2}$ & 0.68 & 0.02 & 0.0677 & 0.0642 & 0.0029 & 0.0023 \\
\hline $\mathbf{2 3}$ & 0.51 & 0.02 & 0.0624 & 0.0679 & 0.0028 & 0.0022 \\
\hline $\mathbf{2 4}$ & 1.64 & 0.02 & 0.0913 & 0.0906 & 0.0025 & 0.0025 \\
\hline $\mathbf{2 5}$ & 2.22 & 0.02 & 0.1263 & 0.1278 & 0.0026 & 0.0026 \\
\hline $\mathbf{2 6}$ & 1.11 & 0.025 & 0.0913 & 0.0717 & 0.0020 & 0.0020 \\
\hline $\mathbf{2 7}$ & 0.68 & 0.025 & 0.0898 & 0.0781 & 0.0024 & 0.0019 \\
\hline $\mathbf{2 8}$ & 0.51 & 0.025 & 0.0791 & 0.0826 & 0.0024 & 0.0019 \\
\hline $\mathbf{2 9}$ & 1.64 & 0.025 & 0.1263 & 0.1102 & 0.0019 & 0.0021 \\
\hline $\mathbf{3 0}$ & 2.22 & 0.025 & 0.1804 & 0.1554 & 0.0019 & 0.0022 \\
\hline $\mathbf{3 1}$ & 1.11 & 0.03 & 0.1126 & 0.0873 & 0.0017 & 0.0018 \\
\hline $\mathbf{3 2}$ & 0.68 & 0.03 & 0.1050 & 0.0950 & 0.0017 & 0.0017 \\
\hline $\mathbf{3 3}$ & 0.51 & 0.03 & 0.1005 & 0.1005 & 0.0018 & 0.0016 \\
\hline $\mathbf{3 4}$ & 1.64 & 0.03 & 0.1537 & 0.1340 & 0.0014 & 0.0019 \\
\hline $\mathbf{3 5}$ & 2.22 & 0.03 & 0.2055 & 0.1890 & 0.0015 & 0.0019 \\
\hline & & & & & & \\
\hline
\end{tabular}




\section{University Library}

\section{- M I N E R VA}

\section{A gateway to Melbourne's research publications}

Minerva Access is the Institutional Repository of The University of Melbourne

\section{Author/s:}

Li, W;Wang, Y;Mumford, KA;Smith, KH;Stevens, GW

Title:

Prediction of holdup and drop size distribution in a disc-doughnut pulsed column with tenova kinetics internals for the water-Alamine 336 system

\section{Date:}

2018-11-01

\section{Citation:}

Li, W., Wang, Y., Mumford, K. A., Smith, K. H. \& Stevens, G. W. (2018). Prediction of holdup and drop size distribution in a disc-doughnut pulsed column with tenova kinetics internals for the water-Alamine 336 system. HYDROMETALLURGY, 181, pp.82-90. https:// doi.org/10.1016/j.hydromet.2018.08.017.

Persistent Link:

http://hdl.handle.net/11343/241467 